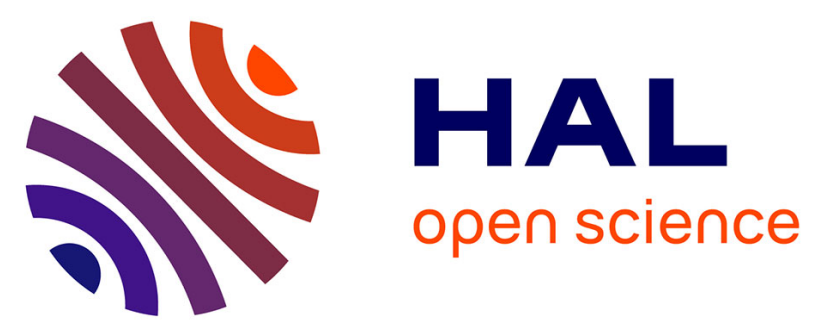

\title{
Comparative assimilation of Topex/poseidon and ERS altimetric data and of TAO temperature data in the tropical Pacific Ocean during 1994-1998, and the mean sea-surface height issue
}

L. Parent, Charles-Emmanuel Testut, Jean-Michel Brankart, Jacques Verron,

Pierre Brasseur, Lionel Gourdeau

\section{To cite this version:}

L. Parent, Charles-Emmanuel Testut, Jean-Michel Brankart, Jacques Verron, Pierre Brasseur, et al.. Comparative assimilation of Topex/poseidon and ERS altimetric data and of TAO temperature data in the tropical Pacific Ocean during 1994-1998, and the mean sea-surface height issue. Journal of Marine Systems, 2003, 40-41, pp.381-401. 10.1016/S0924-7963(03)00026-5 . hal-00212074

\author{
HAL Id: hal-00212074 \\ https://hal.science/hal-00212074
}

Submitted on 14 Jan 2020

HAL is a multi-disciplinary open access archive for the deposit and dissemination of scientific research documents, whether they are published or not. The documents may come from teaching and research institutions in France or abroad, or from public or private research centers.
L'archive ouverte pluridisciplinaire HAL, est destinée au dépôt et à la diffusion de documents scientifiques de niveau recherche, publiés ou non, émanant des établissements d'enseignement et de recherche français ou étrangers, des laboratoires publics ou privés. 


\title{
Comparative assimilation of Topex/Poseidon and ERS altimeter data and of TAO temperature data in the tropical Pacific ocean during 1994-1998, and the mean sea-surface height issue
}

\author{
Laurent Parent ${ }^{\mathrm{a}}$, Charles-Emmanuel Testut ${ }^{\mathrm{a}}$, Jean-Michel Brankart ${ }^{\mathrm{a}}$, \\ Jacques Verron ${ }^{\mathrm{a}}$, Pierre Brasseur ${ }^{\mathrm{a}, *}$, Lionel Gourdeau ${ }^{\mathrm{b}}$ \\ a Laboratoire des Ecoulements Géophysiques et Industriels (LEGI), CNRS, B.P. 53X, 38041 Grenoble Cedex, France \\ b Laboratoire d'Etudes en Ge'ophysique et Oce'anographie Spatiales, UMR5566 CNRS/CNES/IRD/UPS Toulouse,
}

France

\begin{abstract}
Five years of Topex/Poseidon (T/P) and ERS sea level anomaly (SLA) data (1994-1998) are assimilated every 10 days into a primitive equation model of the tropical Pacific ocean. The data assimilation technique used here is a reduced-order Kalman filter derived from the Singular Evolutive Extended Kalman (SEEK) filter [J. Mar. Syst. 16(3-4) (1998) 323] with an error covariance matrix parameterised by a subset of multivariate 3D global empirical orthogonal functions (EOFs). The assimilation run is compared to the free run and to independent data from the TAO network. The impact of sea-surface height (SSH) assimilation on surface and subsurface temperature and currents is estimated in the equatorial band.

In a second stage, temperature data from the TAO array are assimilated in the same conditions as in the first stage. The comparison between the results of the two assimilation experiments is made mainly with a view to gaining insights into the mean sea-surface height (MSSH) for the assimilation of altimeter data, and more generally, into the question of biases.

XBT observations and TAO array data are then used to build a physically more consistent mean sea-surface height for assimilation of SLA data. Results from the assimilation of altimeter data referenced to this new MSSH show significant improvements.
\end{abstract}

Keywords: Assimilation; Mean sea-surface height (MSSH); Pacific Ocean; Altimetry; El Niño

\section{Introduction}

The El Nino-Southern oscillation (ENSO) phenomenon is the most significant process of climate

* Corresponding author. Tel.: +33-4-7682-5072; fax: +33-47682-5271.

E-mail addresses: verron@hmg.inpg.fr (J. Verron), pierre.brasseur@hmg.inpg.fr (P. Brasseur). variability at the interannual time scale in the tropical Pacific ocean, and is now recognized as having an impact on the whole planet. It is now possible to simulate and predict the ENSO phenomenon using coupled ocean/atmosphere numerical models. However, although such simulation tools already exist (e.g., Latif et al., 1993; Delecluse et al., 1998; Barnston et al., 1999), they still need to be improved. A wellknown difficulty with coupled models is related to the 
synoptic initialisation of the system's ocean component. The initial conditions for the ocean have to meet two requirements. First, they must be consistent with the atmospheric component in order to avoid initial shocks due to the necessary adjustments between the two interacting fluids. Second, they must be accurate enough to produce reliable forecasts a few months or more in advance. Indeed, because of the greater heat capacity of the ocean compared to the atmosphere, the memory of the coupled system is held by the ocean. Thus, it is important to obtain an accurate estimate of the ocean initial conditions before forecasting climate variability using coupled models, and data assimilation is a way to do this (e.g., Canizares et al., 2001). Overall, our knowledge of the ocean is limited. The observations available are mainly for the surface whereas ocean dynamics is three dimensional. Moreover, ocean models are far from perfect, largely as a result of poor parameterisation of key physical processes (e.g., vertical mixing) and because our knowledge of atmospheric forcing is not always adequate to constrain ocean models.

The TOGA program and the altimetric satellites (Geosat, Topex/Poseidon (T/P), ERS,...) of the past decade have enabled the scientific community to observe and, in conjunction with ocean models, better understand the dynamics of the tropical Pacific ocean. Currently, a number of different observations are available to oceanographers: (i) firstly from satellites, which give us surface information such as sea-surface height (SSH) or sea-surface temperature (SST) with a high spatial and temporal resolution, (ii) secondly from the development of an in situ array in the tropical Pacific ocean (the TAO network). More recently, ocean satellite observations have also been completed by altimetric data from GFO, Jason, Envisat missions. Innovative satellite measurements are also expected for quantities such as the poorly observed ocean salinity. Regarding the subsurface ocean, the TAO array is extended (e.g., TRITON, PIRATA) and complemented by other observational capabilities such as synoptic float systems (e.g., ARGO). In addition, and in spite of their non-synopticity, XBT data are still a major source of subsurface information in much of the ocean.

In this paper, the ENSO phenomenon is reproduced with hindcast experiments of a forced ocean model. Data assimilation provides estimates of the ocean state by combining model and observations, and may therefore provide a more realistic view of the evolution of the 3D ocean over time. It is clear today that data assimilation has become a more mature tool especially in the tropical oceans where the relatively linear nature of the dynamics makes the technique relatively simple to handle.

Two methods are generally used in data assimilation, the statistical approach of the Kalman filter (e.g., Fukumori, 1995; Gourdeau et al., 2000; hereafter $G 00$ ) or the variational approach (e.g., Greiner and Arnault, 2000; Bonekamp et al., 2001; Vossepoel and Behringer, 2000). Although both the Kalman filter and the variational approach derive from the same estimation problem, their algorithmic implementation in complex ocean models may require different simplifications or approximations, thus leading to different solutions. One basic objective of this paper will be to demonstrate that a statistical assimilation scheme is able to improve the tropical Pacific ocean state simulated by a primitive equation ocean model for the years 1994-1998, a period which encompasses the most important El Niño phenomenon of the past century.

In the present study, the Singular Evolutive Extended Kalman (SEEK) filter (Pham et al., 1998) is used, which is derived from the conventional Kalman filter to assimilate sea level anomaly from $\mathrm{T} / \mathrm{P}$ and ERS satellites and TAO array data. In the first experiment dedicated to the assimilation of SSH (ASS/SSH1 experiment), the TAO temperature profiles are used as independent data to validate the scheme. In particular, they allow the vertical propagation of the surface information to be checked. In the second assimilation experiment (ASS/TAO experiment) in which TAO data are assimilated, T/P and ERS data also provide a means of validation, although more limited. Data from T/P and ERS satellites are only residuals of the sea surface topography and they lack an absolute reference mean sea-surface height (MSSH). In this study, the major objective is to assess how critical this issue of the definition of an adequate MSSH is. The comparison between the assimilation of the two data types is expected to provide some insight in this regard. In the third and last experiment (ASS/SSH2 experiment), SSH data are assimilated again, but with a new reference MSSH provided by TAO and XBT data. 
This paper follows on from two earlier studies, Verron et al. (1999) (hereafter V99) and G00, but with significant changes, most of which are indicated below. In the present study, a full primitive equation model is considered (from top to bottom) whereas previously only a 9-layered reduced-gravity version of the Gent and Cane model was used (see Gent and Cane, 1989). Note also that there is no salt in this version of the Gent and Cane model, only density. V99 and G00 considered only altimeter data and not TAO observations as in the present study. More importantly perhaps, the assimilation time sequence under consideration here covers the unusual event of the 19971998 El Niño/La Niña. This specific period is a challenging period for assimilation and, if successful, the results could open the way for providing support for physical interpretation. Note that promising work is underway in this area using the present simulation results (Dewitte, 2002, personal communication).

The paper is divided into six sections. Following the Introdution, the model and data are described in Section 2. The assimilation scheme and strategy for the hindcast experiments are developed in Section 3. The results of the first SSH assimilation experiment are presented in Section 4. The TAO assimilation and the question of the estimation of mean sea-surface height is discussed in Section 5 as well as a new SSH assimilation experiment. Section 6 summarises the results.

\section{Model and data sets}

\subsection{Model description and forcing}

The assimilation experiments were performed with the OPA model developed at LODYC (Madec et al., 1998), the version used being similar to Vialard et al. (2001). This solves the ocean dynamics primitive equations using the traditional hydrostatic and Boussinesq approximations and assuming a rigid lid at the ocean surface. The equations are solved by a finitedifference scheme on a $\mathrm{C}$ grid with a geopotential coordinate. Temporal integration is based on a leapfrog scheme and the equation of state is computed from the Jackett and Mc Dougall (1995) formulation.

The domain under consideration covers the Tropical Pacific between $120^{\circ} \mathrm{E}-75^{\circ} \mathrm{W}$, and $30^{\circ} \mathrm{S}-30^{\circ} \mathrm{N}$. The zonal resolution is $1^{\circ}$ (171 zonal grid points) and the meridional resolution varies from $0.5^{\circ}$ along the equator to $2^{\circ}$ at the northern and southern boundaries (59 meridional grid points). The northern and southern boundaries are closed. A relaxation of temperature and salinity toward the Levitus climatology is applied between $20^{\circ}$ and $30^{\circ}$ in each hemisphere, with a progressive weight increasing from 0 (no relaxation) at $20^{\circ}$ and below to 1 (full relaxation) at $30^{\circ}$.

The time step is $1.5 \mathrm{~h}$ and the Laplacian operators used for the horizontal mixing of momentum and tracers have an eddy viscosity coefficient of 2000 $\mathrm{m}^{2} \mathrm{~s}^{-1}$ in the equatorial band $\left( \pm 10^{\circ}\right)$, increasing up to $10,000 \mathrm{~m}^{2} \mathrm{~s}^{-1}$ along the northern and southern boundaries. Moreover, the eddy coefficient increases linearly to $7000 \mathrm{~m}^{2} \mathrm{~s}^{-1}$ within $5^{\circ}$ of the western boundary to reduce numerical noise.

Along the vertical, there are 25 levels with a $10 \mathrm{~m}$ resolution at the surface and a $1000 \mathrm{~m}$ resolution at the bottom. There are therefore 19 levels in the first $500 \mathrm{~m}$ depth where the major part of equatorial dynamics takes place. The vertical mixing of momentum and tracers is parameterised by a turbulent kinetic energy (TKE) model (Blanke and Delecluse, 1993). For the unstable situations, an enhanced vertical mixing parameterisation is used which sets the vertical mixing coefficient to $0.5 \mathrm{~m}^{2} \mathrm{~s}^{-1}$ when the BruntVäisälä frequency is negative.

The surface boundary conditions include heat, freshwater and momentum fluxes. In tropical oceans, the ocean dynamics is mostly forced by wind stresses. $\mathrm{Fu}$ et al. (1993) found that the major part of the variance in sea level observations is due to winddriven equatorial waves. It is therefore important to have adequate knowledge of wind stress fields to force ocean models. Grima et al. (1999) have studied the sensitivity of the OPA model to various wind stress forcings from satellite data or atmospheric models. Their conclusions are that the use of ERS wind data tends to produce more realistic thermocline and zonal currents than those obtained using wind stress data from the French Meteorological Office's Arpege-Climat model (conclusions are similar from the atmospheric model of NCEP and ECMWF). In this study, ERS scatterometer-derived wind stresses (Bentamy et al., 1996) are therefore used and complemented by TAO-derived stresses (Menkes et al., 1998). These ERS + TAO wind stress forcing data are available with a weekly frequency. 
Regarding heat and freshwater fluxes, NCEP reanalyses (Kalnay et al., 1996) are used with a daily frequency. Sea-surface temperatures (SST) provided by ocean and atmospheric models (NCEP, ECMWF) often have certain inconsistencies due to the fact that heat and freshwater fluxes are not well known. To limit these inconsistencies, a flux correction factor is classically applied to parameterise the net heat flux. Following Barnier et al. (1995), we obtain:

$$
Q_{\text {net }}(\mathrm{SST})=Q_{\mathrm{NCEP}}+\frac{\partial Q}{\partial \mathrm{SST}}\left(\mathrm{SST}_{\mathrm{mod}}-\mathrm{SST}_{\mathrm{NCEP}}\right) .
$$

The relaxation is made toward the NCEP SST and the restoring coefficient $\partial Q / \partial \mathrm{SST}$ is fixed at $-40 \mathrm{~W}$ $\mathrm{m}^{-2} \mathrm{~K}^{-1}$. In addition, a feedback term is applied to the freshwater forcing using sea surface salinity fields from the Levitus climatology. This avoids the problem of sea-surface salinity climatological drift.

To illustrate model performance, a time longitude diagram is presented in Fig. 1 showing anomalies of sea-surface height (SLA) from the T/P + ERS altimetric data (see the next section for details on the data) and the free simulation (without assimilation) of the OPA model over the 1994-1998 period. In the tropical Pacific ocean, the equatorial dynamics is dominated by the propagation of Kelvin and Rossby waves which have a strong signature in terms of $\mathrm{SSH}$, especially during the warm phase (El Niño) and the cold phase (La Niña) of the ENSO phenomenon. The small structures which appear in the time longitude diagram of the $T / \mathrm{P}+$ ERS altimetric signal are due to the finer resolution of the data $\left(1 / 4^{\circ}\right)$ compared to that of the model $\left(1^{\circ}\right)$.

There is good agreement in phase between the model and the observations throughout the 19941998 period. The 1994 and especially the $1997 \mathrm{El}$ Niño are well simulated, as is the 1998 La Niña. However, discrepancies between model and data are observed for the amplitude of the negative anomalies in the middle of the basin in January-February 1994, March 1995, July-August 1995 and in the second half of 1998. In fact, the model overestimates the amplitude of these negative anomalies in JanuaryFebruary 1994, March 1995, and July-August 1995, while it underestimates the amplitude during the 1998 La Niña. This is only a sea-surface view and it will be seen in Section 4 that other discrepancies also exist in the subsurface ocean (e.g., thermocline structure) and for currents.

\subsection{Altimetric and in situ data sets}

\subsubsection{Altimetric data}

The altimetric data used in this study were generated from the T/P Geophysical Data Record processed by the Aviso altimetry group. They include an inverted barometer correction to remove the sea level static response to atmospheric pressure changes. The SLA fields were calculated by combining $\mathrm{T} / \mathrm{P}$ and ERS (hereafter called T/P + ERS) altimeter data. They were then mapped using a space-time objective analysis method which takes into account the orbit error correlated at long wavelengths. SLA are available on a $0.25^{\circ} \times 0.25^{\circ}$ grid at 10-day intervals. In our study, SLA data from January 1994 to December 1998 are referenced to an average computed from the January 1993-December 1995 period. The accuracy of these SLA altimetric data is estimated at $3 \mathrm{~cm}$ RMS.

As data are only residuals (SLA) of the true SSH, a mean sea-surface height (MSSH) has to be provided for the computation of the innovation vector term. In the first stage of this study, the MSSH is estimated from a free run of the model itself, averaged over the 1994-1996 period. In the second stage, the MSSH is estimated from in situ (XBT and TAO) data. As far as the validation of results is concerned, the difficulty of MSSH definition could have been bypassed by considering anomalies only. It was decided not to do this, however, in order to underline the nature of the problem.

Thus, the T/P+ERS SSH data used for reference are:

- In the first case, the above Aviso SLA to which the model-derived MSSH (called MSSH1) is added. These data are called SSH1 $(\mathrm{SSH} 1=\mathrm{SLA}+$ MSSH1).

- In the second case, the same SLA to which the dataderived MSSH (called MSSH2) is added. These data are called $\mathrm{SSH} 2(\mathrm{SSH} 2=\mathrm{SLA}+\mathrm{MSSH} 2)$.

In the assimilation experiments, no prior estimation of the MSSH error was taken into account. As it corre- 

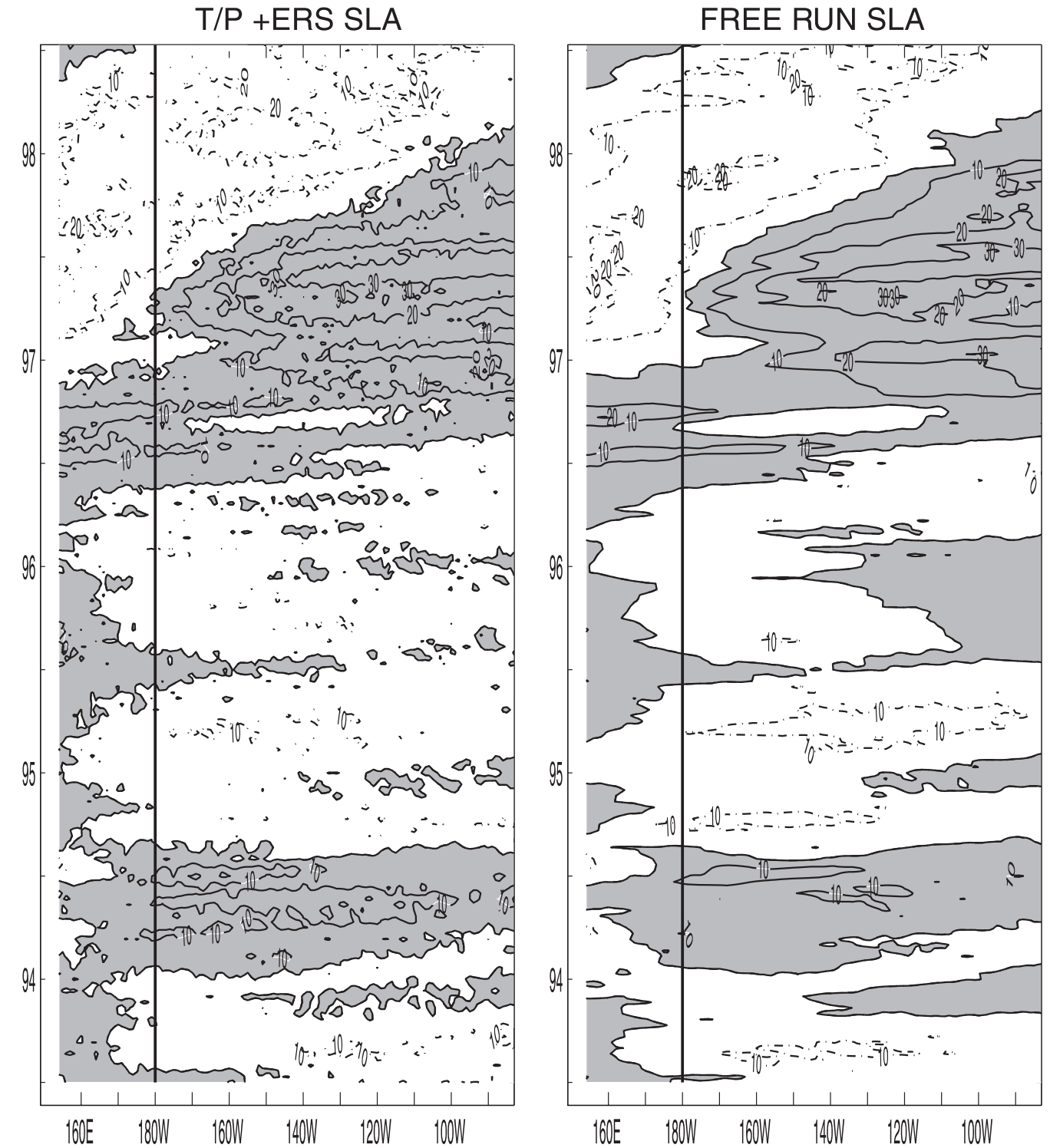

Fig. 1. Time longitude diagram of T/P + ERS SLA data (left) and free run simulation SLA (right). Contour $10 \mathrm{~cm}$, shading above $0 \mathrm{~cm}$. The $180^{\circ}$ longitude is represented by the straight line.

sponds to a bias, it cannot in principle enter into the filter statistics in the same way as SLA errors since all variables are supposed to be centered.

\subsubsection{TAO data}

The TAO array consists of approximately 70 moorings in the tropical Pacific ocean, located between $8^{\circ} \mathrm{N}-8^{\circ} \mathrm{S}$, and $137^{\circ} \mathrm{E}-95^{\circ} \mathrm{W}$, and at depths ranging from 0 to $500 \mathrm{~m}$. They provide high-quality measurements of temperature profiles on a continuous basis (the accuracy of the data is estimated at $0.1{ }^{\circ} \mathrm{C}$ ). The 5-day averaged data available on the TAO web site are used for validation and a time interpolation is applied to the data to enable comparisons with model simulations when necessary. In addition, ADCP vertical profiles of zonal current are measured at 6 specific 
moorings of the TAO array. These moorings are located along the equator at $147^{\circ} \mathrm{E}, 156^{\circ} \mathrm{E}, 165^{\circ} \mathrm{E}$, $170^{\circ} \mathrm{W}, 140^{\circ} \mathrm{W}, 110^{\circ} \mathrm{W}$. The accuracy of these data is estimated at $2 \mathrm{~cm} \mathrm{~s}^{-1}$.

\section{Data assimilation method and strategy}

\subsection{Data assimilation method}

The SEEK filter used here is derived from the Kalman filter theory (Pham et al., 1998). It is well known that one of the major limitations of the Kalman filter approach lies in the handling of the error covariance matrix $(P)$. There are two main reasons for this:

- First, because of its dimension $n \times n$ where $n$, is the dimension of the state vector ( $n$ is about $10^{7}$ for current ocean models). The storage and handling of such a matrix is impossible with current machines.

- Second, because of the problem of estimating all the components of this matrix, especially at initial time.

Cane et al. (1996) argue that imperfect knowledge of error structures (mainly the system error covariance matrix $\mathbf{P}$ and the model error covariance matrix $\mathbf{Q}$ ) makes the full Kalman filter superfluous. Thus, keeping a reduced number of degrees of freedom $(d f)$ in the error space is advisable in order to obtain an adequately conditioned assimilation scheme. But the criteria to establish the reduced number of degrees of freedom are not easy to define and depend on both the model dynamics and the observation system.

The reduced Kalman filter introduced by Pham et al. (1998) is based on a decomposition of the error covariance matrix on a reduced-order basis. The error basis is allowed to evolve over time according to nonlinear model dynamics or/and residuals of the innovation vector. Theoretical aspects are described in earlier publications (Pham et al., 1998; V99; Brasseur et al., 1999). The filter was applied with some success to real situations (e.g., G00; Brankart et al., in press; Testut et al., this issue). In the following section, the theory of the SEEK filter is only briefly commented on, as it has already been described in earlier papers.

The initial error covariance matrix is represented by a limited number of three-dimensional, multivari- ate empirical orthogonal functions (EOFs) describing the dominant modes of free-model variability. This method of reduction has already been used by Cane et al. (1996) to assimilate tropical Pacific tide gauges into a version of a shallow-water model with two vertical modes. In this case, the initial error covariance matrix can be represented as:

$\mathbf{P}^{0}=S \Delta^{0} S^{\top}$

where $S$ represents the $r$ EOF directions of the reduced basis and $\Delta$ gives their amplitude. As the number of EOFs selected is much smaller than the dimension of the state $(r \ll n)$, it is now possible to actually implement a Kalman filter.

During the $t_{k}$ analysis step of the Kalman filter, the analysis state $x^{\mathrm{a}}\left(t_{k}\right)$ is computed from the forecast state $x^{\mathrm{f}}\left(t_{k}\right)$, the set of observations $y_{k}$ and the corresponding model variables $H_{k} x^{\mathrm{f}}\left(t_{k}\right)$ by

$x^{\mathrm{a}}\left(t_{k}\right)=x^{\mathrm{f}}\left(t_{k}\right)+\mathbf{K}_{k}\left[y_{k}-H_{k} x^{\mathrm{f}}\left(t_{k}\right)\right]$

with a gain matrix $\mathbf{K}_{k}$ which is written as follows:

$\mathbf{K}_{k}=S_{k} \Delta_{k}^{\mathrm{a}}\left(H_{k} S_{k}\right)^{\top} \boldsymbol{R}_{k}^{-1}$

and

$\Delta_{k}^{\mathrm{a}}=\left[\left(\Delta_{k}^{\mathrm{f}}\right)^{-1}+\left(H_{k} S_{k}\right)^{\top} \mathbf{R}_{k}^{-1}\left(H_{k} S_{k}\right)\right]^{-1}$

where $y_{k}$ is the observation at time $t_{k}, H$ is the observation operator and $\mathbf{R}$ the observation error matrix. As usual, the exponents a and $\mathrm{f}$ denote the analysis and forecast states. The analysis and forecast covariance matrices at time $t_{k}$ can be expressed as:

$\mathbf{P}^{\mathrm{a}}=S_{k} \Delta_{k}^{\mathrm{a}} S_{k}^{\top} \quad$ and $\quad \mathbf{P}^{\mathrm{f}}=S_{k} \Delta_{k}^{\mathrm{f}} S_{k}^{\top}$

The analysis state may be rewritten as:

$$
\begin{aligned}
x^{\mathrm{a}}\left(t_{k}\right)= & x^{\mathrm{f}}\left(t_{k}\right)+S_{k}\left(\Delta_{k}^{\mathrm{a}}\right)^{1 / 2} \\
& \times\left(H_{k} S_{k}\left(\Delta_{k}^{\mathrm{a}}\right)^{1 / 2}\right)^{\top} \mathbf{R}_{k}^{-1}\left[y_{k}-H_{k} x^{\mathrm{f}}\left(t_{k}\right)\right]
\end{aligned}
$$

The analysis step can be interpreted as a correction to the forecast step made from a combination of the EOFs with a weight proportional to the projection of the innovation vector. The reduced basis of EOFs will be useful to the correction only if the innovation vector does not have a null projection in the error sub-space. 
The SEEK filter normally includes the non-linear equation of propagation for the error covariance matrix. Here, it has not been fully included because it was shown by V99 and G00 that due to the quasilinear dynamics of the tropical Pacific ocean, the improvement in results was not significant in relation to the numerical cost. However, it does not mean that the covariance matrix is steady $\left(\mathbf{P}_{t_{k}} \neq \mathbf{P}_{0}\right)$ : the error sub-space remains the same during the experiment but the projection of the error modes in the sub-space $\left(\Delta_{k}\right)$ evolves with the internal statistics of the SEEK filter (Eq. (5)). In this context, the additional numerical cost of the assimilation is only a few percent of the free run simulation cost.

\subsection{Experimental strategy}

Fig. 2 shows the various temporal stages of the experiment. The OPA model is spun up from rest and Levitus climatology for 2 years with climatological NCEP heat and freshwater fluxes and ERS/TAO wind stresses. Then, the model is run for 7 years starting in 1992 with an interannual forcing.

A comparison with TAO data was made in January 1993 and this showed that the mean structure, as evidenced in terms of temperature profiles, is substantially different (see, for example, the mean location of the $20{ }^{\circ} \mathrm{C}$ isotherm). Thus, following G00, the model was reinitialised with a thermal structure which is more consistent with the January 1993 in situ data (than the Levitus climatology). The model was then run for the year 1993, with interannual fluxes to stabilise its trajectory, and the experiments (with and without assimilation) were conducted from January 5, 1994 to December 31, 1998 with ERS + TAO weekly and NCEP daily observed fluxes.

\subsubsection{State vector and restart}

The state vector used in these experiments contains temperature, salinity, the two components of horizontal velocity, and sea-surface height ( $\mathrm{SSH}$, linked to sea-surface pressure by $\mathrm{SSH}=P_{\mathrm{s}} / \rho_{0} g$ ). There are about 700,000 df, which define the dimension of the state vector. In principle, all variables of the state vector are assumed to be independent. In practice, however, it is useful to keep some dependent variables in the state vector such as the SSH. If this variable is not included, temperature, salinity and velocity should be converted to SSH through the use of a highly nonlinear observation operator.

As the SEEK filter is a sequential algorithm, the assimilation proceeds through successive reinitialisations of the model at each analysis step. According to the rigid-lid approximation, the divergence of the barotropic flow must vanish. Due to the fact that there are regions where no correction is applied (buffer zones) and to the specific way of writing the OPA code, this constraint cannot be strictly verified. The divergent contribution of the correction must therefore be removed to allow the model to be restarted.

By definition, the state vector is related to some unique instant. To restart the model at each assimilation step, an Euler time step is implemented before reusing the leap-frog temporal scheme.

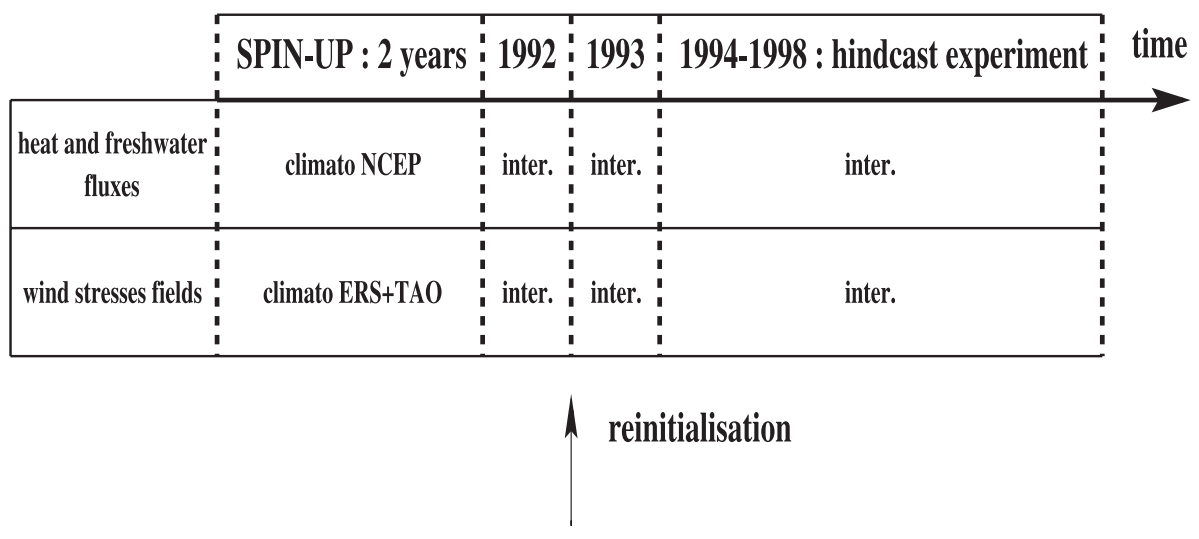

Fig. 2. Strategy of the hindcast experiments. 
In addition, at each restart step, the turbulent kinetic energy used to estimate the vertical eddy coefficient is updated by a few iterations (less than 10 in practice) of the vertical mixing routine to produce turbulent kinetic energy in agreement with the temperature, salinity and the two components of the horizontal velocity of the analysis state.

\subsubsection{EOF analysis}

The reduced basis of the SEEK filter is estimated from an EOF analysis of the free run (without assimilation) over the 5-year integration period (1994-1998) and thus includes some seasonal and interannual variability. The EOFs are multivariate, linking all variables, including $\mathrm{SSH}, T, S$ and velocity, in 3D space. They have a physical meaning, revealing the many structures of variability in the tropical Pacific ocean at the scale of the entire basin. These EOFs are computed from 90 model states, sampled every 20 days during the 1994-1998 period. After sensitivity studies, 15 EOFs were selected to determine the reduced basis, and these EOFs explain $93 \%$ of model variance.

The SSH component of the first multivariate EOF is shown in Fig. 3, together with the corresponding temporal function. The figure reveals the west-east seesaw (Wyrtki, 1985), which is the most important feature of the El Niño and La Niña phases of the ENSO phenomenon. In 1997, the warm pool of the western basin flows toward the eastern basin and produces a positive SLA, whereas during the La Niña phase (second part of 1998) the opposite is observed. Interannual variability is mainly contained in this EOF (the second EOF completes the first EOF with the equatorial/off-equatorial seesaw, not shown here).
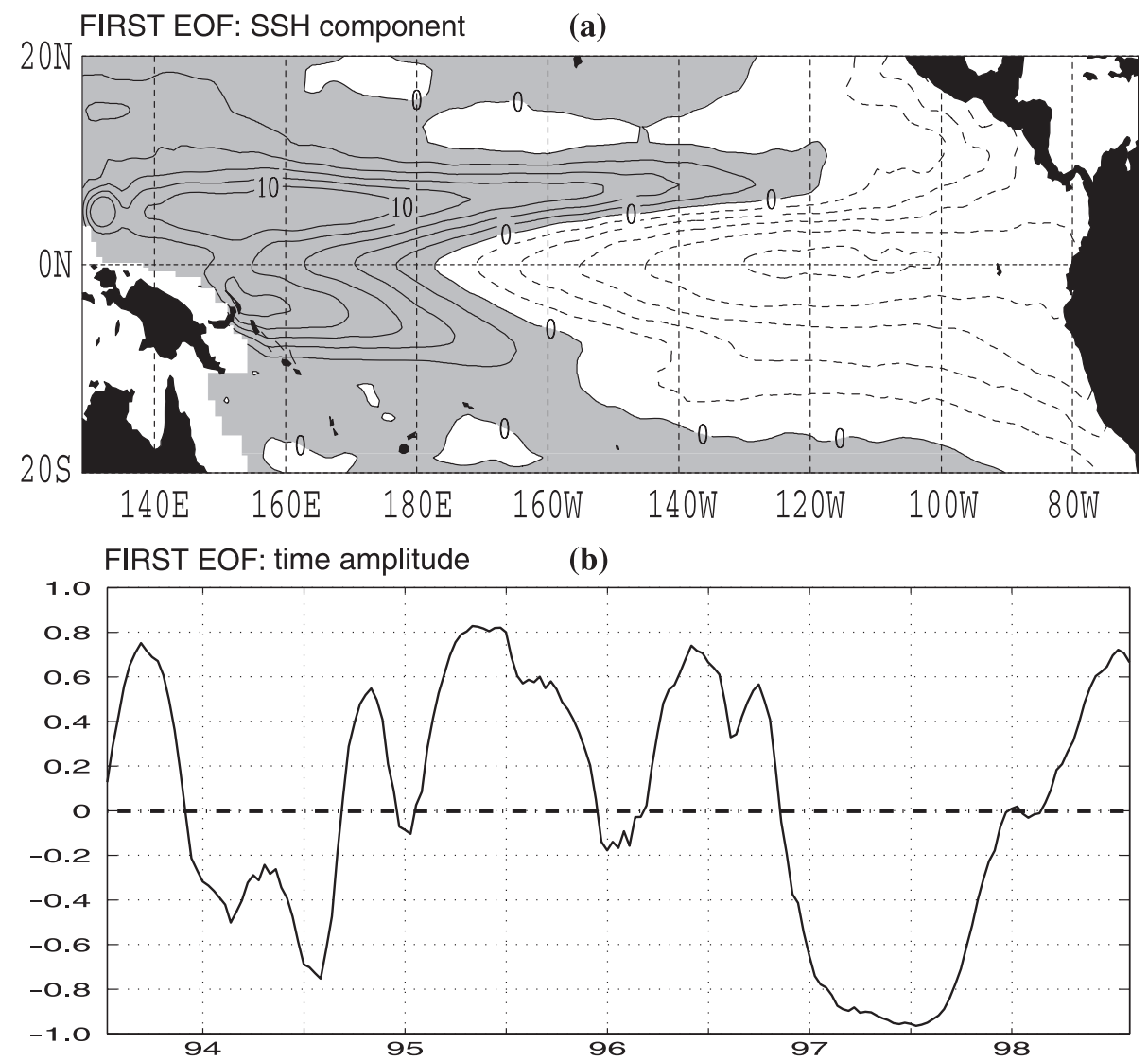

Fig. 3. SSH component of the first EOF (in $\mathrm{cm}$ ) (a), and its associate time function (b) from the free simulation. Contour $2 \mathrm{~cm}$, shading above $0 \mathrm{~cm}$. 
These EOFs are fairly similar to the EOFs calculated by Delcroix (1998), who analysed the seasonal and interannual variability of the tropical Pacific ocean using different observations. For use in the assimilation process, the EOFs have been normalized using the standard deviation of each variable, based on the variability of the free-run model.

\subsubsection{Implementation aspects}

The observation error matrix (R) for altimetric data is a diagonal matrix with a 3 -cm RMS error. A more realistic parameterization of $\mathbf{R}$ should ideally include a contribution representing the correlated errors associated with the gridding process of the original observations. Sensitivity experiments (not reported here), however, did not reveal this parameter to have a significant influence.

The observation operator $H$ is a bilinear interpolation of the model grid to the observation grid when the $\mathrm{T} / \mathrm{P}+$ ERS SLA data are assimilated. Regarding TAO data (temperature profiles), which are used as independent data to validate the assimilation scheme, the interpolation is trilinear, first with a bilinear interpolation along the horizontal, then with a single linear interpolation along the vertical. Unlike the mapped SLA data, for which the observation operator is constant with time, the TAO array produces data whose spatial distribution evolves in time. This means that the observation operator also evolves over time.

During the assimilation, only data between $\pm 20^{\circ}$ were used. Beyond $20^{\circ}$, there are buffer zones where the correction is switched off. Between latitudes $20^{\circ} \mathrm{N}$ and $20^{\circ} \mathrm{S}$, the applied correction is fully statistical (thanks to multivariate global EOF) and no further physical adjustment is needed. Multivariate correlations between $\mathrm{SSH}$, temperature, salinity and velocity are the means by which information is transmitted to all non-observed components of the state vector. In particular, surface altimeter data are propagated downward along the vertical to correct for other variables describing the ocean's characteristics below the surface.

\section{Assimilation of sea-surface height (ASS/SSH1 experiment)}

This section discusses the results of a hindcast experiment in which $\mathrm{T} / \mathrm{P}$ and ERS satellite altimeter data are assimilated every 10 days over the 19941998 period. As stated earlier, the model-based MSSH (MSSH1) is computed from the years 1994-1996. The sum of MSSH1 and SLA are actually assimilated. All physical fields (such as the SST or T maps) are the results of the forecast states rather than the analysis states. Table 1 summarizes the definition of the different experiments conducted and the corresponding notations in the figures.

\subsection{Validation with respect to the assimilated data}

RMS differences (RMSD) between SSH1 assimilated data and SSH model predictions are shown in Fig. 4 for the free run and the assimilation run. During the free simulation (FREE experiment), the SSH RMSD has an average value of $5.8 \mathrm{~cm}$, which is relatively small. It suggests that the model tends to simulate the SSH variable well. On the other hand, there is a steady increase of this RMSD over time with some maxima in the winter of 1995-1996 and during the El Niño (1997) and La Niña (1998). The assimilation of T/P + ERS SSH1 enables the RMSD to be decreased by $1 \mathrm{~cm}$ (average value of $4.8 \mathrm{~cm}$ ). The difference between the analysis states and the forecast states is very small $(0.1 \mathrm{~cm}$ RMS), which suggests that the statistical correction on prognostic variables $(T, S, U, V)$ is consistent with the model dynamics. This is actually an important result which shows that the corrections provided by the assimilation are basically consistent with the model equations and conservation laws in particular. In fact, the assimilation

Table 1

Definitions of the experiments and legend of the graph lines used

\begin{tabular}{llll}
\hline & FREE & No data & $\begin{array}{l}\text { Thin solid } \\
\text { black line }\end{array}$ \\
\hline $\begin{array}{c}\text { No. } 1 \\
\begin{array}{l}\text { assimilation } \\
\text { experiment }\end{array}\end{array}$ & ASS/SSH1 & $\begin{array}{l}\text { SSH1 = SLA + MSSH1 } \\
\text { (Model-based MSSH) }\end{array}$ & $\begin{array}{l}\text { Thin solid } \\
\text { black line }\end{array}$ \\
$\begin{array}{c}\text { No. } 2 \\
\text { assimilation } \\
\text { experiment }\end{array}$ & ASS/TAO & TAO & $\begin{array}{l}\text { Thin solid } \\
\text { black line }\end{array}$ \\
$\begin{array}{c}\text { No. } 3 \\
\text { assimilation } \\
\text { experiment }\end{array}$ & ASS/SSH2 & $\begin{array}{l}\text { SSH2 }=\text { SLA + MSSH2 } \\
\text { (Data-based MSSH) }\end{array}$ & $\begin{array}{l}\text { Thin dashed } \\
\text { black line }\end{array}$ \\
& Data & & $\begin{array}{l}\text { Thin } \\
\text { dot-dashed } \\
\text { black line }\end{array}$ \\
\hline
\end{tabular}




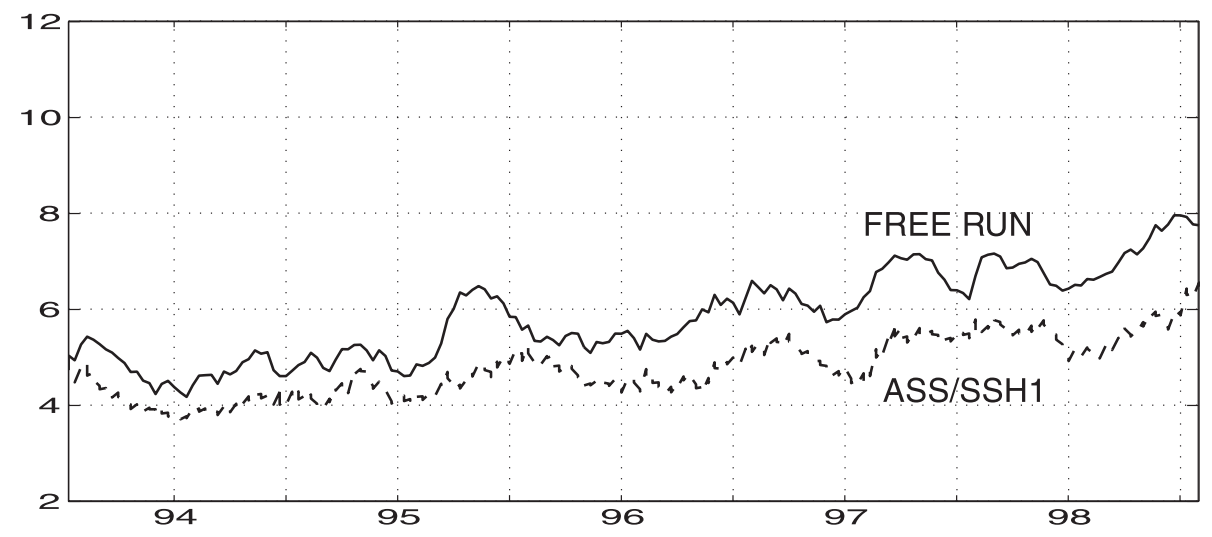

Fig. 4. Evolution of the RMSD (in $\mathrm{cm}$ ) between T/P + ERS SSH1 data and the free simulation SSH (FREE experiment, solid line), and the firstassimilation experiment SSH (ASS/SSH1 experiment, dashed line). Analysis and forecast states are represented on the same curve, which is the case in all subsequent similar curves of the figures.

needs some time to become efficient. After one and a half years, a more significant decrease in the RMSD is observed.

In Fig. 5, the SSH variances of the observations for the free run and assimilation run are shown between $20^{\circ} \mathrm{N}$ and $20^{\circ} \mathrm{S}$. The El Niño phenomenon has a very strong impact on SSH variability in 1997 (around $300 \mathrm{~cm}^{2}$ ). The free run tends to simulate this peak of variance very well and the main discrepancy concerns seasonal variability (1994-

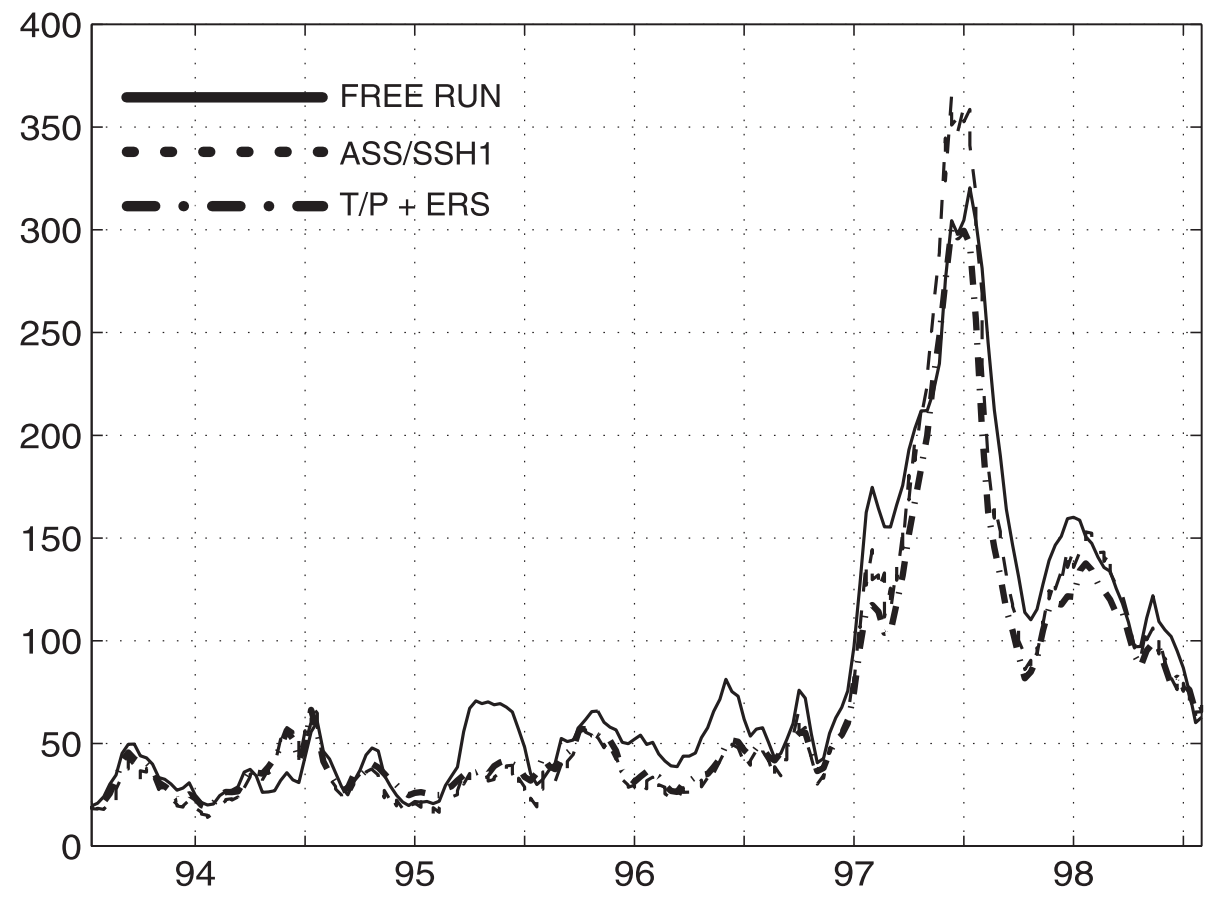

Fig. 5. Variance of the SSH signal (in $\mathrm{cm}^{2}$ ): T/P + ERS SSH1 data (thick dot-dashed black line), free simulation SSH (FREE experiment, solid line), and first-assimilation experiment SSH (ASS/SSH1 experiment, dashed line). 
1996). The assimilation run follows the observations quite well and clearly improves the SSH variance during the 1994-1997 period. It has, however, a negative effect on the peak of El Niño since it overestimates it.

The SSH variability maps for the 1994-1998 period are presented for the observations and the model (with and without assimilation) in Fig. 6. There are three major regions of variability:

- Along the equator in the Eastern Pacific, representing the propagation of Kelvin waves but also, and probably mainly, the slower modes of the coupled ocean/atmosphere system.
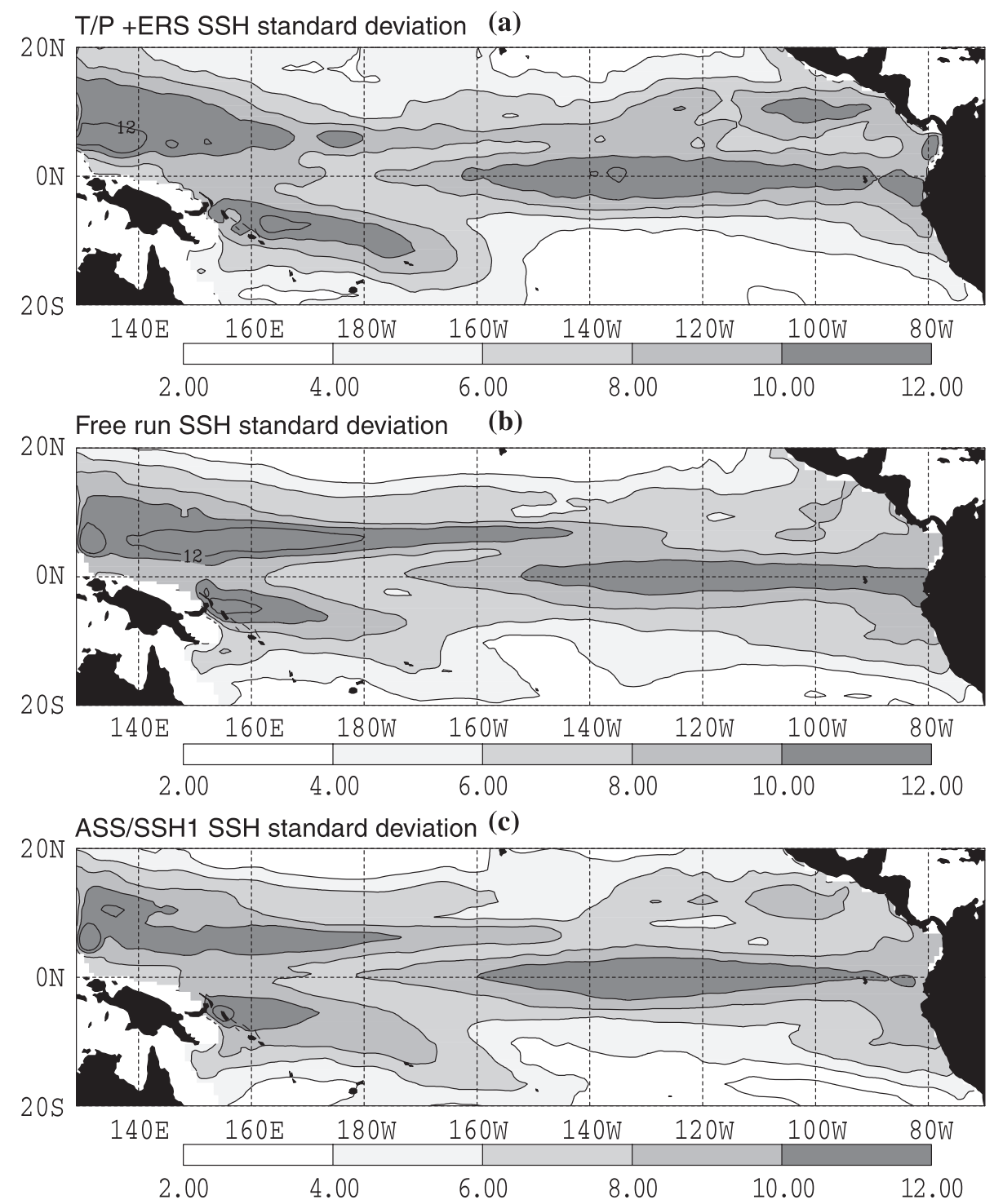

Fig. 6. Standard deviation of the SSH signal (in cm) over the 1994-1998 period: (a) T/P + ERS SSH1 data, (b) free simulation SSH (FREE experiment) and (c) the first-assimilation experiment SSH (ASS/SSH1 experiment). 
- In the Western basin, where two maxima of variability are seen around $5^{\circ} \mathrm{N}$ and $5^{\circ} \mathrm{S}$, close to the positions of the ITCZ and SPCZ. This variability includes first mode Rossby wave activity but also a lot of externally forced variability.

The free run tends to simulate these three maxima of variability well but the Rossby waves at $5^{\circ} \mathrm{N}$ are too intense, whereas the zonal extension is too wide and in the southern hemisphere the region of maximum variability is not wide enough. The assimilation reduces the main discrepancies between the model and observations, especially in the region of maximum variability located at $5^{\circ} \mathrm{N}$. However, there is a negative effect in the most easterly part of the basin, along the equator (near the coast) where the assimilation run produces a slight decrease in variability $(10.6 \mathrm{~cm}$ for the T/P + ERS data, $9.7 \mathrm{~cm}$ for the free run and $9.2 \mathrm{~cm}$ for the assimilation run).

In fact, the assimilation of $\mathrm{T} / \mathrm{P}+\mathrm{ERS}$ data reduces the SSH RMSD almost everywhere. In the equatorial band, the RMSD of the free simulation is less than 5 $\mathrm{cm}$, while the assimilation produces a slight but noticeable improvement. More significantly, the assimilation enables a reduction in the error along the $10^{\circ} \mathrm{N}$ latitude and the RMSD is decreased there by about $3.5 \mathrm{~cm}(11 \mathrm{~cm}$ for the free simulation and 7.5 $\mathrm{cm}$ for the assimilation simulation). A slight degradation is observed near the northern and southern boundaries, where there is a transition between cor- rected regions and non-corrected regions (buffer zones).

\subsection{Validation with respect to independent data}

\subsubsection{Thermal structure}

The overall RMSD between temperature profiles from the TAO network and their model counterparts is shown in Fig. 7. Note that this global difference is calculated by using a trilinear interpolation of the model grid onto the observation grid. As for the SSH RMSD, the curve tends to diverge slightly over time with an increase of about $1{ }^{\circ} \mathrm{C}$ during the 1994 1998 period, reaching $2.5{ }^{\circ} \mathrm{C}$ during the La Niña phenomenon (second half of 1998). The assimilation results in a large decrease in the temperature RMSD, with a gain of about $1{ }^{\circ} \mathrm{C}$ in 1998 which actually counterbalances the intrinsic drift of the model from reality. Some time is needed for the system to adjust (about 2 years). As previously, there is no divergence between the analysis state and the forecast state, suggesting that the assimilation performs consistently with the model.

In Fig. 8, the mean depth of the $20{ }^{\circ} \mathrm{C}$ isotherm is represented, averaged on the TAO network. This isotherm is of physical relevance because in the tropical regions the thermocline is located around this isotherm $\left(16-24{ }^{\circ} \mathrm{C}\right)$. The El Niño phenomenon has a strong impact on the mean depth of the $20{ }^{\circ} \mathrm{C}$ isotherm, with a $20 \mathrm{~m}$ difference compared with the mean state (around $125 \mathrm{~m}$ ). The free run tends to

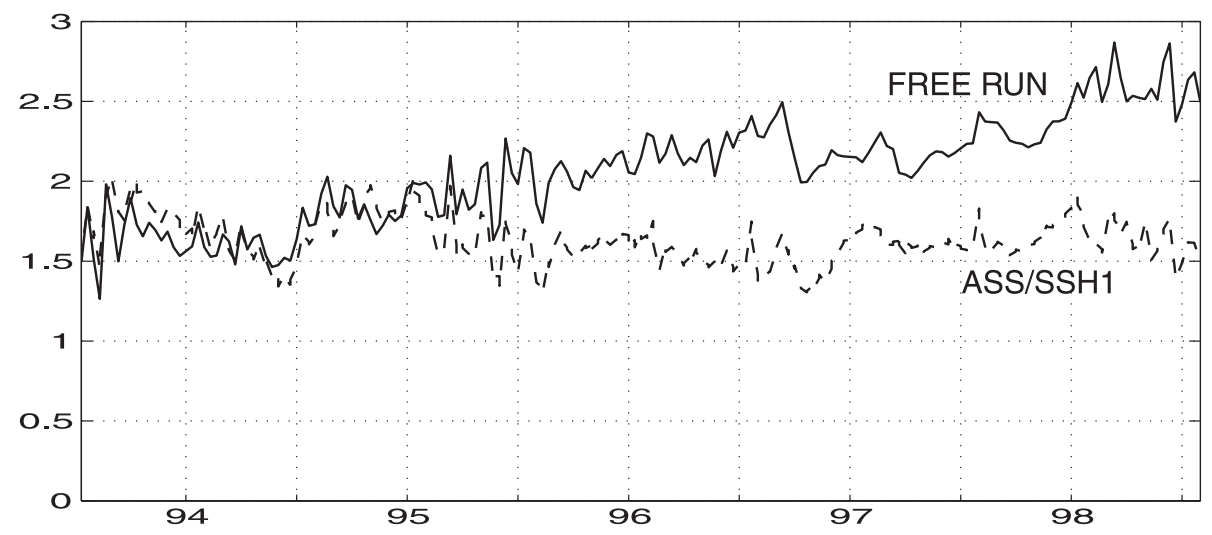

Fig. 7. Evolution of the RMSD (in ${ }^{\circ} \mathrm{C}$ ) between temperature profiles of the TAO network and the free simulation temperature (FREE experiment, solid line), and the first-assimilation experiment temperature (ASS/SSH1 experiment, dashed line). 


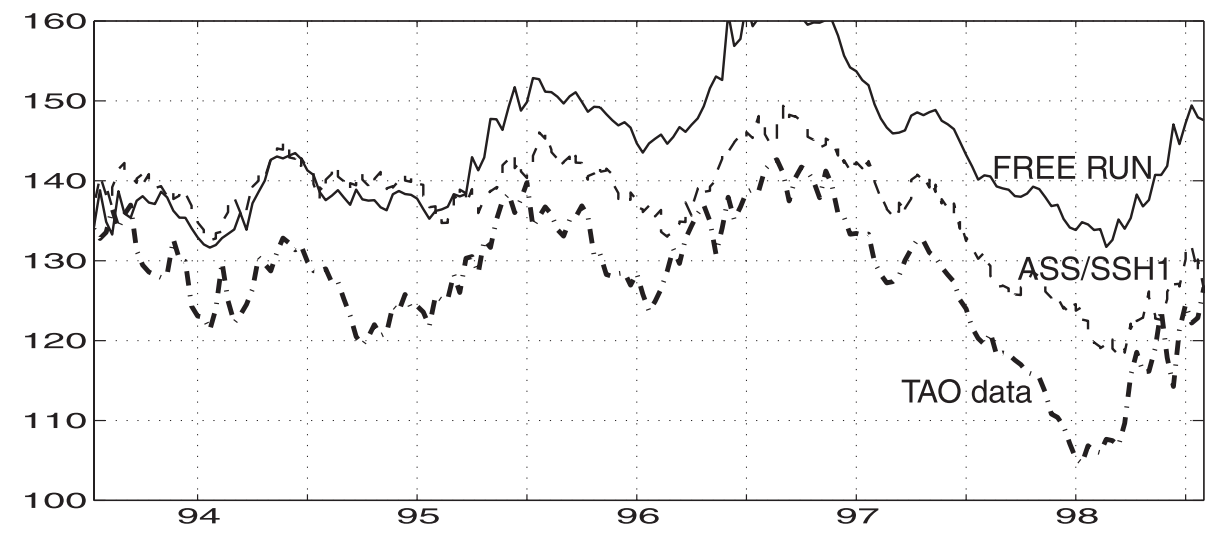

Fig. 8. Evolution of the $20{ }^{\circ} \mathrm{C}$ isotherm mean depth (in $\mathrm{m}$ ) on the TAO network: TAO data (thick dot-dashed black line), the free simulation (FREE experiment, solid line) and the first-assimilation experiment (ASS/SSH1 experiment, dashed line).

diverge dramatically during the $1994-1998$ period, with a bias of about $25 \mathrm{~m}$ in 1998, but seasonal and interannual variability are well simulated. The assimilation counterbalances this tendency with a gain of about $15-20 \mathrm{~m}$ in 1998. Again, as stated earlier, it takes some time before the positive impact of assimilation is observed.

Fig. 9 shows the vertical location of the errors along the Equator. In fact, the temperature errors are confined within the thermocline area. The assimilation produces a more realistic thermocline, which is shallower and less diffuse than in the free simulation. In the eastern basin, the equatorial upwelling is better simulated, and there is a decrease in the temperature RMSD of almost $1{ }^{\circ} \mathrm{C}$. Later in the paper, we will see how this allows a better simulation of the equatorial undercurrent (EUC) along the equator.

With regard to temperature variability (no figure shown), the assimilation increases the standard deviation in the eastern basin (along the thermocline) to 3.5 ${ }^{\circ} \mathrm{C}$, whereas the free run produces a $3{ }^{\circ} \mathrm{C}$ standard deviation. This is still too low compared with observed rates $\left(4{ }^{\circ} \mathrm{C}\right)$. Elsewhere, there is no marked improvement or degradation in the variability of the thermal structure, probably because the free model is already satisfactory.

\subsubsection{Zonal currents}

The assessment is limited here to the 6 current profilers from the TAO array, located along the equator. In the tropical Pacific ocean, the circulation is mainly composed of two major currents along the equator (Fig. 10):

- Along the thermocline, the EUC flows from the west $(200 \mathrm{~m})$ and reaches the surface in the eastern basin, bringing warm water;

- At the surface, the South Equatorial Current (SEC) flows to the western basin and advects cold water.

In addition, there is the convergence zone $(\mathrm{CZ})$ in the western basin, with a minimum of velocity.

When comparing free model and observations, it is observed that: the EUC is too weak and too diffuse (along the vertical axis), whereas at the surface the SEC is too intense (more than $0.2 \mathrm{~m} \mathrm{~s}^{-1}$ ) and the $\mathrm{CZ}$ is not well simulated. The assimilation (Fig. 10) correctly produces a more intense EUC but it is still too diffuse in comparison with ADCP observations. The SEC is more realistic with a less intense velocity than in the free run. In the eastern basin, the $\mathrm{CZ}$ is better simulated.

A degradation is observed in the western basin at $100 \mathrm{~m}$ depth with the negative velocity core. This negative velocity actually represents a branch of the New Guinea Coastal Undercurrent. In reality, it is located further to the west (following the New Guinea coast), but as the bathymetry of the model is drastically smoothed and far from realistic in this region, the New Guinea Coastal Undercurrent is spuriously located in the model simulations. Since the North Equatorial Counter Current (NECC), which flows at 

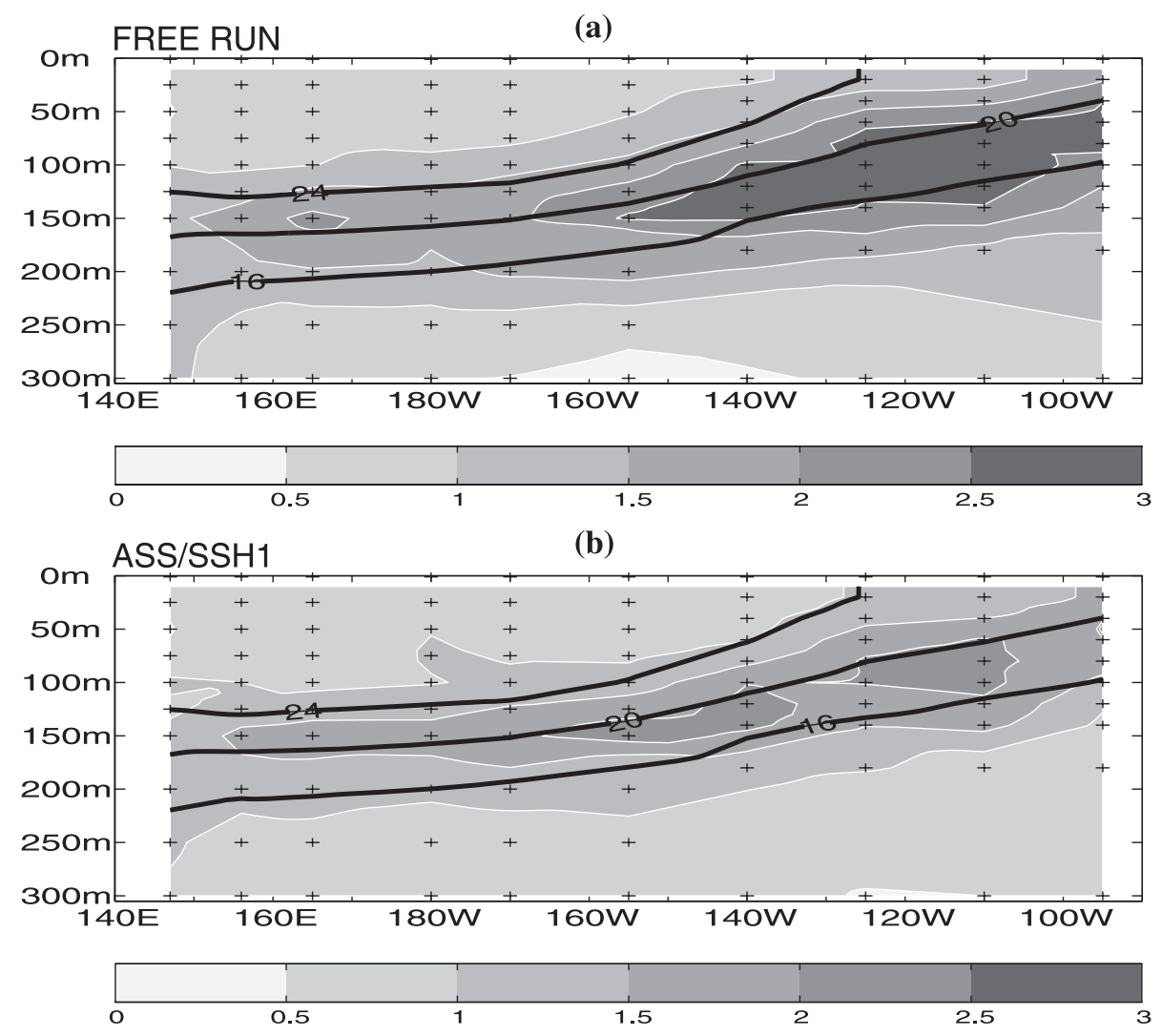

Fig. 9. RMSD (in ${ }^{\circ} \mathrm{C}$ ) along the equator between temperature profiles of the TAO network (over the 1994-1998 period) and the free simulation temperature (FREE experiment, (a)), and the first-assimilation experiment temperature (ASS/SSH1 experiment, (b)). The thick black lines correspond to the mean depths of the $16-20-24{ }^{\circ} \mathrm{C}$ isotherms from the TAO data.

$5^{\circ} \mathrm{N}$ between the western and the eastern basins (not shown here), is more intense in the assimilation run, it induces a more intense New Guinea Coastal Undercurrent. This leads to a relatively high negative core of zonal velocity in this region, whereas in the real ocean it is located much further west. This problem is therefore mostly a consequence of the model configuration.

\section{Assimilation of TAO data: the MSSH problem}

In the previous section, a hindcast assimilation experiment of $\mathrm{T} / \mathrm{P}+\mathrm{ERS}$ altimetric data was performed for the 1994-1998 period, with an MSSH obtained from a free model simulation. The results were then assessed using independent data from the TAO network, indicating that the SEEK filter applied to the OPA model was able to produce a better estimate of the Tropical Pacific 4D ocean structure. However, a question that needs to be addressed now concerns the relevance of this initial MSSH1 based on the free model simulation.

Blayo et al. (1994) have demonstrated the efficiency of using an MSSH obtained from real hydrographic data and an inverse model, in the case of a limited-area North Atlantic quasi-geostrophic model. They also used an iterative approach to update the MSSH in a consistent manner with the circulation model. Similarly, in the present study, the use of an MSSH from the free model simulation is open to question. To clarify this point, another experiment is conducted which assimilates TAO temperature data directly, i.e. data that are not built from anomalies to which an uncertain MSSH is added (as in the case of the SSH), but data that are absolute signals. 

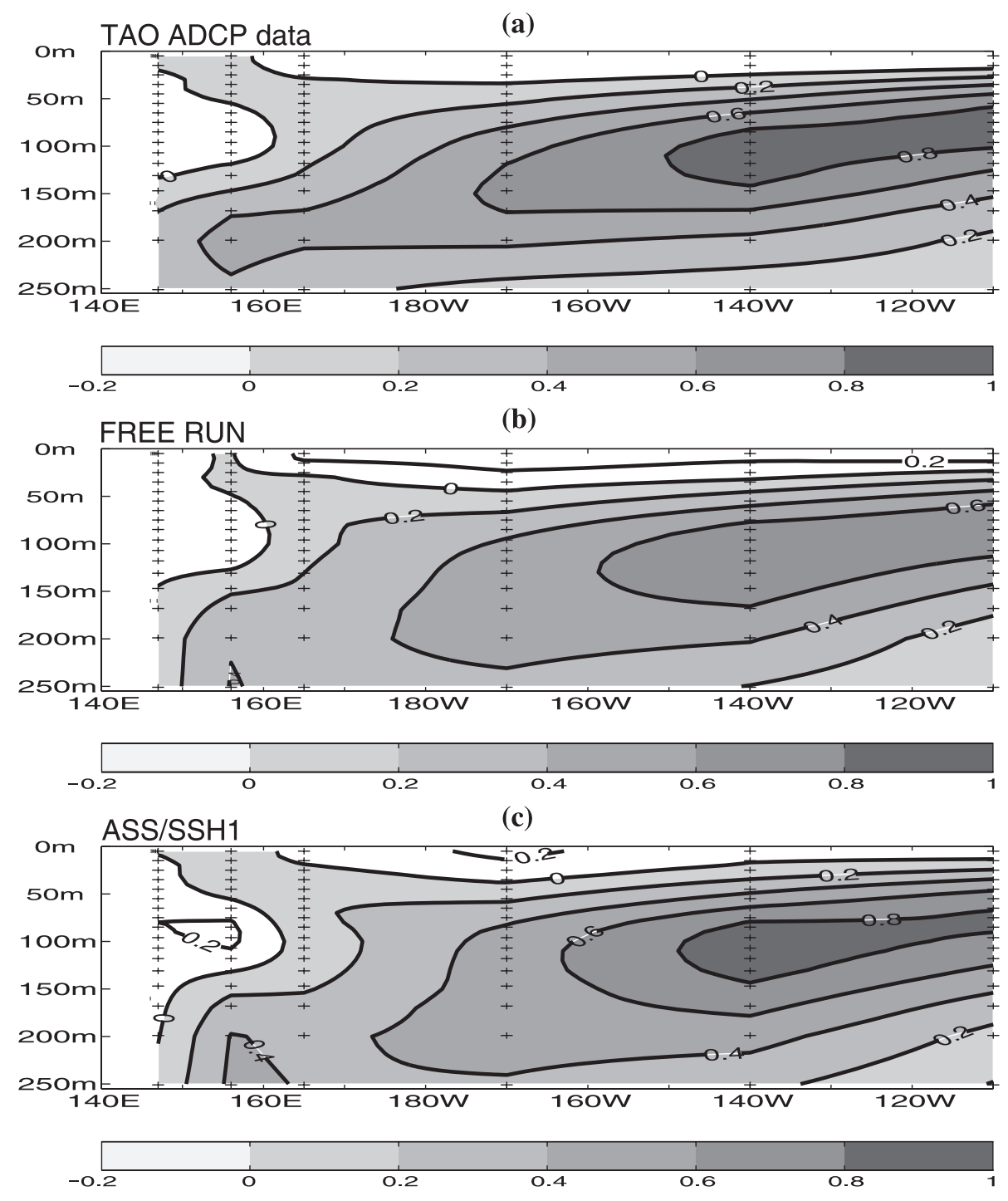

Fig. 10. Mean velocity (in $\mathrm{m} \mathrm{s}^{-1}$ ) along the equator over the 1994-1998 period: (a) TAO ADCP data, (b) free simulation velocity (FREE experiment) and (c) first-assimilation experiment velocity (ASS/SSH1 experiment).

\subsection{Evidence of an MSSH problem: assimilation of TAO data (ASS/TAO experiment)}

The protocol of this ASS/TAO assimilation experiment is the same as for the previous experiment (i.e., ASS/SSH1 experiment). The same reduced basis initialized from an EOF analysis of model variability is used. The observation error matrix is diagonal, with a $0.15{ }^{\circ} \mathrm{C}$ RMS error, and temperature profiles are assimilated every 10 days (same dates as the T/P
+ ERS data). This new ASS/TAO experiment is also performed for the 1994-1998 period.

Fig. 11 shows the temperature RMSD between TAO data and the free simulation (FREE experiment), the simulation with SSH1 data assimilated (ASS/ SSH1 experiment), and the simulation with TAO data assimilated (ASS/TAO experiment). Compared to the ASS/SSH1 experiment, the assimilation of TAO data reduces a large part of the temperature RMSD immediately (first analysis steps), whereas some time is 


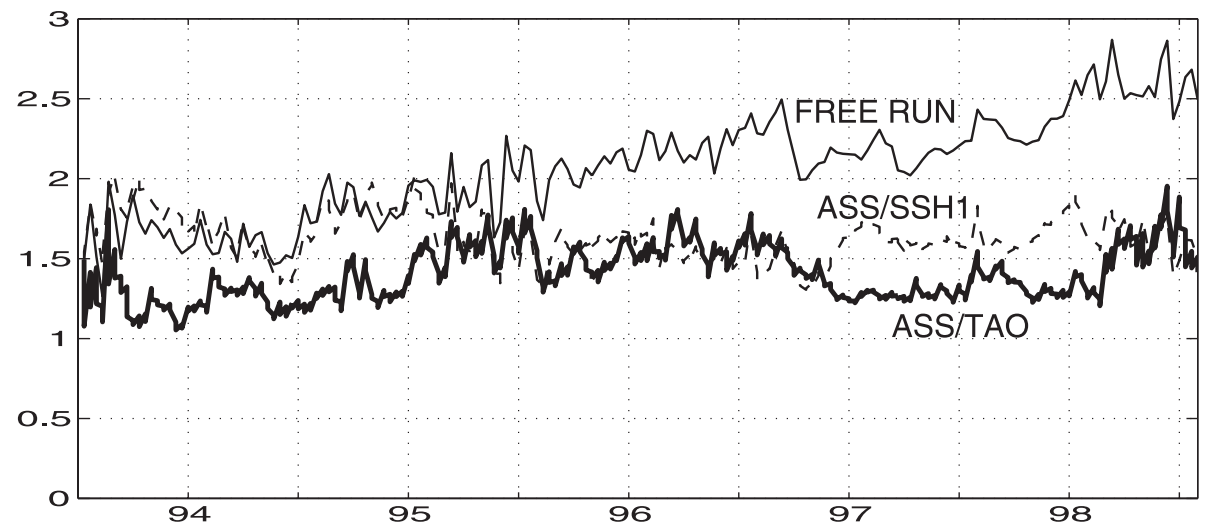

Fig. 11. Evolution of the RMSD (in ${ }^{\circ} \mathrm{C}$ ) between temperature profiles of the TAO network and the free simulation temperature (FREE experiment, thin solid line), and the first-assimilation experiment temperature (ASS/SSH1 experiment, thin dashed line), and the secondassimilation experiment temperature (ASS/TAO experiment, thick solid line).

needed for a reduction to occur when T/P + ERS SSH1 data are assimilated. However, after 2 years, the results are rather similar, with a decrease of the RMSD of about $1{ }^{\circ} \mathrm{C}$ in 1998 (that is about $40 \%$ of the free model error).

To assess this ASS/TAO experiment in terms of $\mathrm{SSH}$, a comparison with the original T/P + ERS SSH1 data is made (Fig. 12). The TAO assimilation results in a marked bias (about $9 \mathrm{~cm}$ RMSD on average), significantly higher than the free model run and the ASS/SSH1 assimilation experiment.

To understand how the assimilation of TAO changes the whole SSH signal, the temporal evolution of the SSH and the total dynamic height at the $170^{\circ} \mathrm{W}-8^{\circ} \mathrm{N}$ point (the total dynamic height is computed from the TAO array) are represented in Fig. 13. It can be seen that the T/P + ERS data, the FREE experiment and the ASS/SSH1 experiment exhibit the same behaviour, but that the ASS/TAO experiment produces a SSH shift right from the beginning of the experiment. Now, let us look at the evolution over time of the total dynamic height. It may be observed that the free run (FREE experiment) has a bias of about $20 \mathrm{~cm}$ over the period and that the assimilation of SSH1 (ASS/SSH1 experiment) reduces this bias, although some time is needed and the correction is only partial. Finally, when the TAO data are assimilated, the bias is reduced immediately and almost

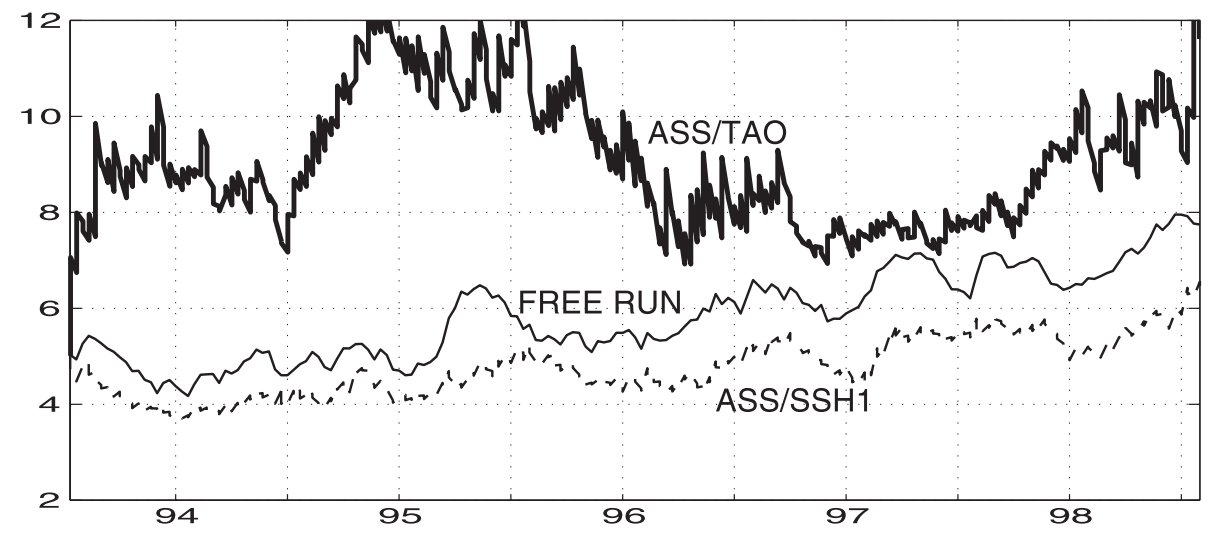

Fig. 12. Evolution of the SSH RMSD (in $\mathrm{cm}$ ) between T/P + ERS SSH1 data and the free simulation SSH (FREE experiment, solid line), and the first-assimilation experiment SSH (ASS/SSH1 experiment, thin dashed line), and the second-assimilation experiment SSH (ASS/TAO experiment, thick solid line). 
(a)

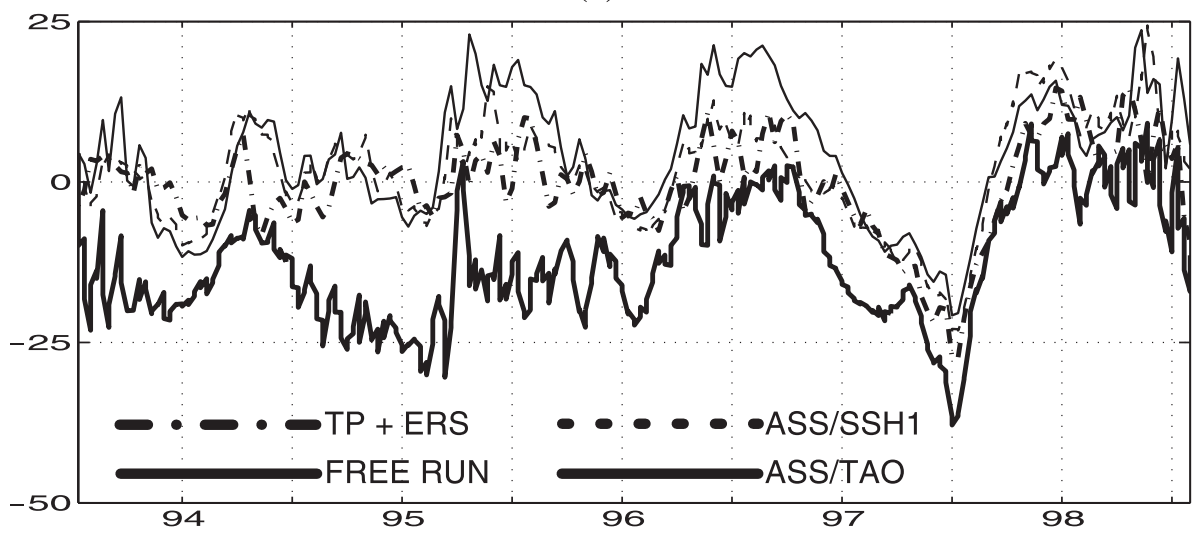

(b)

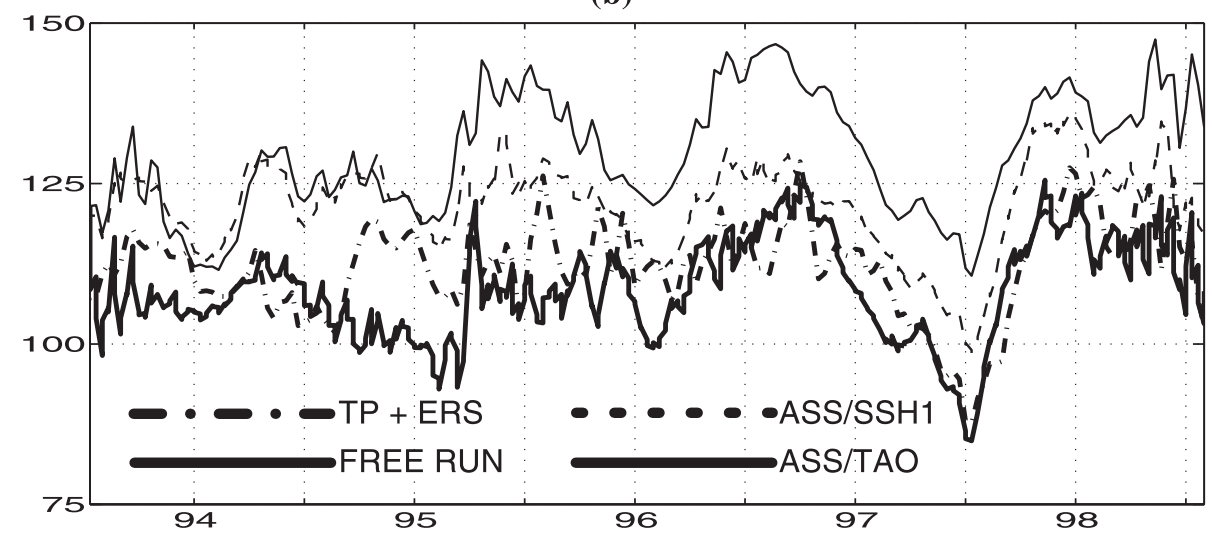

Fig. 13. Evolution of the sea-surface height ((a), in $\mathrm{cm})$ and of the total dynamic height ((b), in $\mathrm{cm})$ : T/P + ERS SSH1 data (thick dot-dashed black line), free simulation SSH (FREE experiment, thin solid line), first-assimilation experiment SSH (ASS/SSH1 experiment, thin dashed line), second-assimilation experiment SSH (ASS/TAO experiment, thick solid line).

totally. The conclusion is therefore quite clear: the MSSH computed earlier from the model is inadequate, whereas an MSSH computed from the TAO data base should provide more satisfactory results. As observed by Blayo et al. (1994), one can improve the prediction by using an MSSH obtained from a complementary data source rather than using the free model only.

\subsection{Experiment with a new MSSH (ASS/SSH2 experiment)}

In the ASS/SSH2 experiment, the assimilation is performed using a new MSSH (MSSH2) provided by in situ data. Since TAO data can provide a dynamic height but not a mean sea-surface height directly, one has to further assume that the physical signal con- tained in the SSH and the total dynamic height, referenced to $500 \mathrm{db}$, are the same. Note that Picaut et al. (1995) found that an $\sim 0.6 \mathrm{~cm}$ RMS error occurs when the dynamic height is used as an alias of the SSH.

A mean dynamic height was thus calculated from in situ data. TAO data were used together with all available XBT data. In fact, the mixed XBT + TAO data base from IRD in Nouméa (available for the 1979-1996 period) was used for the temperature, and the Levitus climatology for the salinity. The resolution of the IRD data base is $5^{\circ}$ in longitude and $1^{\circ}$ in latitude. A bilinear gridding method was then employed to project the information onto the model grid. Next, the mean total dynamic height was evaluated. Fig. 14 shows how different this new MSSH2 


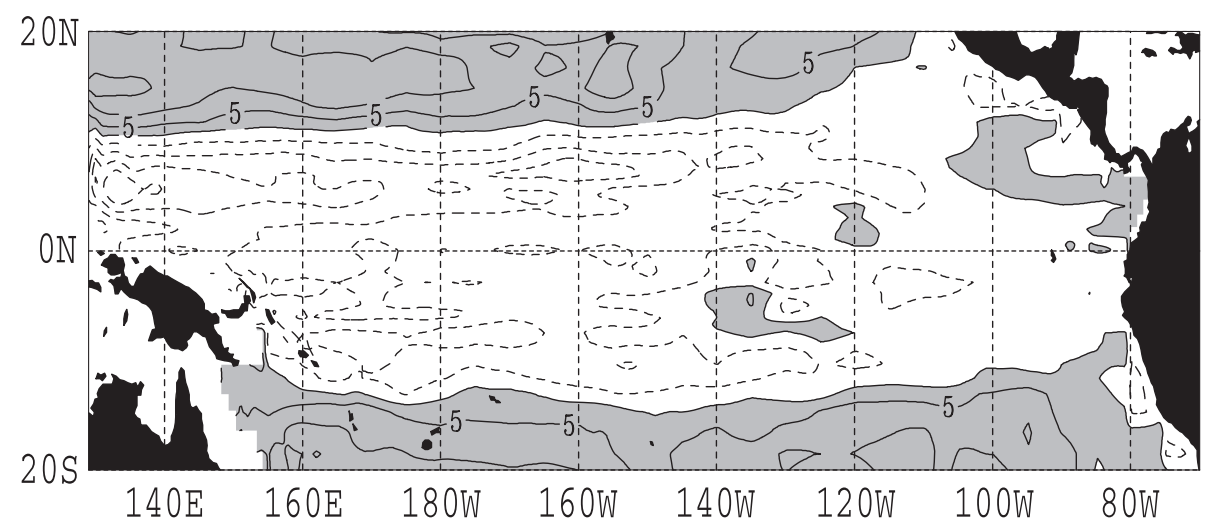

Fig. 14. MSSH differences (MSSH2 - MSSH1) (in $\mathrm{cm}$ ) between XBT + TAO observation MSSH (MSSH2) and the free simulation MSSH (FREE experiment, MSSH1). Contour $5 \mathrm{~cm}$, shading above $0 \mathrm{~cm}$.

is with regard to the initial MSSH1, used in the ASS/ SSH1 experiment. In particular, it is clear that MSSH1 is too high in the equatorial band, especially in the western basin, along the $8^{\circ} \mathrm{N}$ latitude, but too low elsewhere.

The new ASS/SSH2 experiment was then performed, where the assimilation of T/P + ERS data took into account the new MSSH, i.e. SSH2 data. The experimental protocol was the same as before. The SSH RMSD between T/P + ERS data and the ASS/SSH2 experiment together with other experiments is shown in Fig. 15. The new ASS/SSH2 experiment provides a net decrease in the RMSD (5.7 $\mathrm{cm}$ on average) in comparison with the ASS/
SSH1 experiment $(9.1 \mathrm{~cm}$ on average). Note that the main correction occurs during the first analysis step.

It should be remembered that the lack of reference error for the MSSH bias makes it difficult to compare the results of Section 4.1 and the present results (in order, for example, to compare Figs. 4 and 15). Only relative error decreases must be considered: the SSH RMSD was, on average, $5.8 \mathrm{~cm}$ for the free run and $4.8 \mathrm{~cm}$ for the ASS/SSH1 experiment (that is a $20 \%$ decrease in the error), and the SSH RMSD was down from $9.1 \mathrm{~cm}$ RMS for the same ASS/SSH1 experiment to $5.7 \mathrm{~cm}$ RMS for the ASS/SSH2 experiment (that is, a further decrease of $35 \%$ ). The conclusion is then clear: the definition of an adequate MSSH

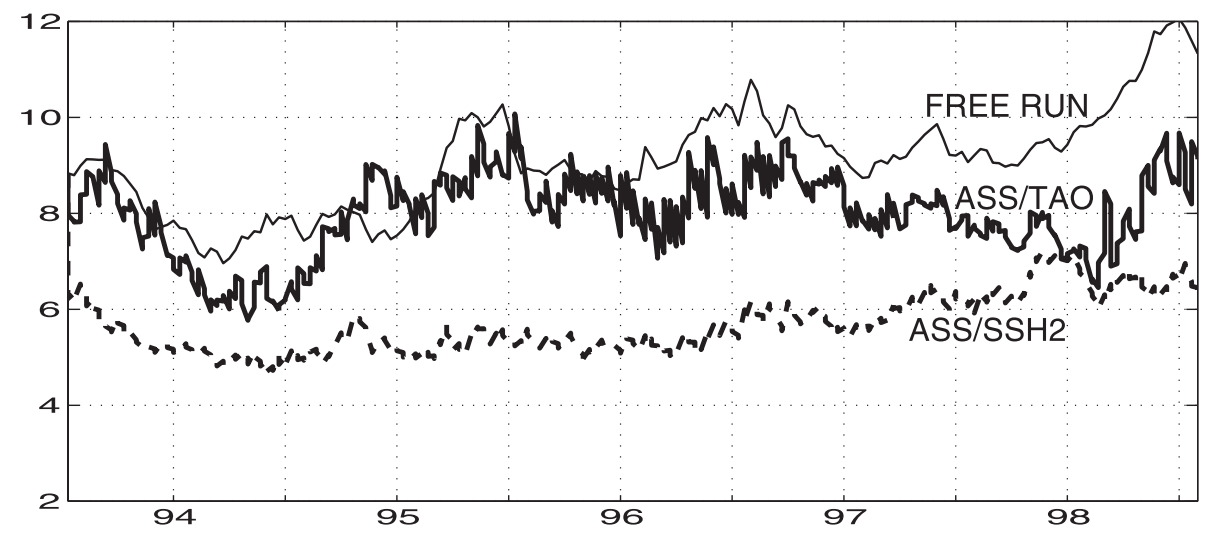

Fig. 15. Evolution of the RMSD (in $\mathrm{cm}$ ) between T/P + ERS SSH1 data and the free simulation SSH (FREE experiment, thin solid line), and the second-assimilation experiment SSH (ASS/TAO experiment, thick solid line) and the third-assimilation experiment SSH (ASS/SSH2 experiment, thick dashed line). 


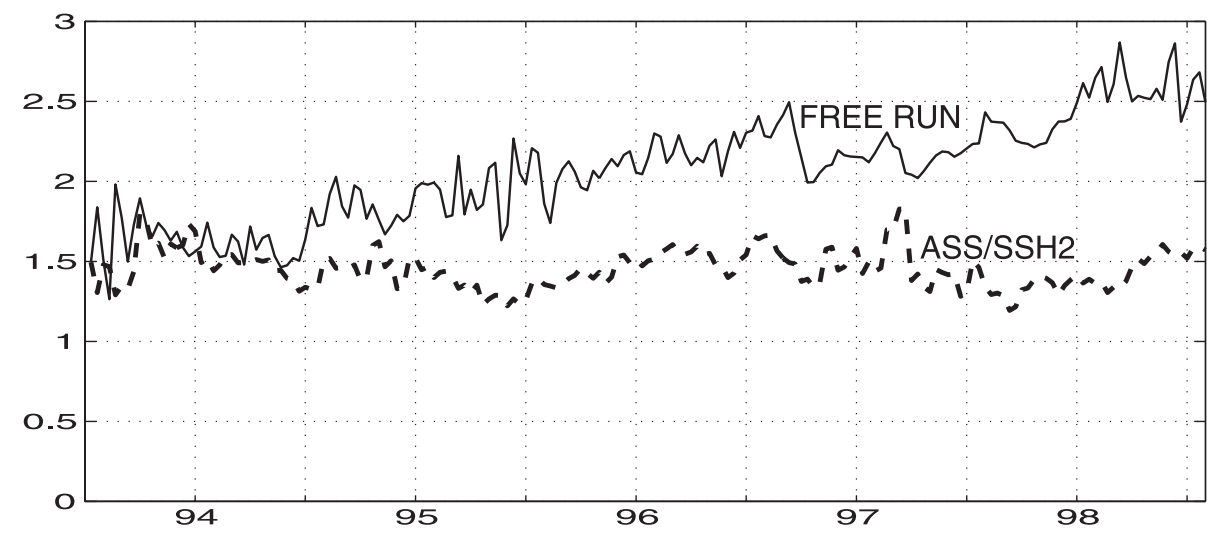

Fig. 16. Evolution of the RMSD (in ${ }^{\circ} \mathrm{C}$ ) between temperature profiles of the TAO network and the free simulation temperature (FREE experiment, solid line) and the third-assimilation experiment temperature (ASS/SSH2 experiment, thick dashed line).

reference for the SSH data to be assimilated has a crucial bearing on the results.

To further assess the ASS/SSH2 experiment, TAO data can also be used but they are not strictly independent since they were already used to estimate the new MSSH. The most important impact of the ASS/SSH2 assimilation experiment concerns the decrease in the temperature RMSD during the second year of the experiment (Fig. 16). The assimilation of the new MSSH is as efficient as the assimilation of TAO data, except for the first 2 years (1994-1995). Compared to the ASS/SSH1 experiment (Fig. 7), the average gain for the global temperature RMSD is $0.3{ }^{\circ} \mathrm{C}$. This is consistent with a sea-level elevation (thermal expansion effect) of about $9 \mathrm{~cm}$ RMS, which is the average RMSD between the two mean seasurface heights used, MSSH1 and MSSH2.

To further validate these experiments, it would be interesting to have other data that are not used for the assimilation scheme, for example, other XBT data or subsurface float data. Such validation data, however, are not numerous enough, particularly for the subsurface ocean. Improved assessment is the only way to really validate model and data assimilation performances and, ultimately, to further improve these tools.

\section{Conclusion}

This paper describes the assimilation of altimeter (T/P and ERS satellite) and temperature (TAO array) data into a primitive equation model of the tropical
Pacific ocean for the 1994-1998 period. The assimilation method, which is a sub-optimal version of the SEEK filter by Pham et al. (1998), uses a reducedorder error covariance matrix represented by a limited number of multivariate global EOFs (the number of 15 EOFs was found to be an optimum). This EOF basis is held constant, but the weights of the different EOFs evolve dynamically with the internal statistics of the SEEK filter.

Firstly, the assimilation of the SSH data is based on an MSSH computed from the free model run. Altimeter data assimilation improves the model solution, even if the free run performs quite well as a result of the prior quality of the wind forcing data. A decrease in the SSH RMSD is obtained and the assimilation restricts the free mode divergence. More especially, it allows a decrease in the model error around latitude $10^{\circ} \mathrm{N}$. The results of this first altimeter data assimilation experiment were assessed with respect to independent TAO data. The RMSD between temperature profiles from the TAO network and their model counterparts decreases by about $1{ }^{\circ} \mathrm{C}$ at the end of the experiment. A period of about one and a half years is required to improve the state of the whole system. The assimilation produces a better thermocline, which is shallower and less diffuse. The equatorial upwelling is better simulated in the eastern basin and the bias in terms of temperature profile is reduced by about $1{ }^{\circ} \mathrm{C}$ near the thermocline. The temporal evolution of the mean depth of the $20{ }^{\circ} \mathrm{C}$ isotherm is also better simulated, and the model trajectory is stabilised. Even if the model was reinitialised with in situ data in 
January 1993, this result means that the forced ocean model needs to be continuously controlled by the assimilation to compensate for its intrinsic drift. Additional work is needed to produce better initial conditions, more consistent with all the available in situ data and with a better resolution than the standard climatologies. In terms of velocity, the assimilation gives a more intense EUC at the subsurface and a less intense SEC at the surface, producing a more realistic circulation along the equator.

The assimilation of temperature profiles from the TAO network provides interesting results which indicate the existence of a bias when compared to the earlier results. When SSH data are assimilated, the bias lies in the fact that the absolute SSH signal is not known, only the anomalies (SLA). A mean sea-surface height must be added to the SLA data in order to perform assimilation. When TAO temperature data are assimilated, such a problem is not encountered although TAO data are much less numerous than altimeter data. In fact, this may lead to other deficiencies in the control of small-scale ocean features. Regarding the MSSH issue, assimilating TAO data indicates the way to proceed. A new MSSH is built based on TAO data complemented by XBT data from historical records. The results obtained with this new MSSH are rather significant and bring the final RMS error level down by $35 \%$ with respect to the first altimeter data assimilation.

In this paper, multi-data assimilation was not performed since we aimed at first developing a progressive strategy to understand the different stages involved:

- The assimilation of altimetric data, because they are unique observations of the ocean state available for the entire planet and for a decadal period.

- The assimilation of temperature profiles from the TAO array. Further work needs to be done on the assimilation of these specific data. Results shown here are encouraging but TAO moorings are sparse on the horizontal and have a limited vertical extension. Refinement of the data assimilation technique is needed to better extract information from this specific type of data.

This paper has clearly shown the importance of defining a precise MSSH when using altimeter data.
Following the last two assimilation experiments (ASS/TAO and ASS/SSH2 experiments), the way is now open to consider the assimilation of multiple data sets $(\mathrm{SSH}+\mathrm{SST}+$ temperature profiles). This is clearly a way of resolving the difficulty associated with the absence of absolute references for altimeter data. However, this issue may be considerably reconsidered with new satellite missions (CHAMP, GRACE, GOCE) by providing a much more reliable reference. However, the more general question of biases will probably remain a challenge from a data assimilation perspective which will need to be addressed. In any case, it is difficult to get away from the assimilation of multiple data sets (in nature, space and time distribution) if the aim is to reach a proper representation (and understanding) of the full 3D ocean over a period of time long enough for climate variability studies.

\section{Acknowledgements}

This study was supported by CNES (contracts 1999-2000 and 2000-2001). We would like to thank IRD and in particular Yves Du Penhoat (IRD, Toulouse) and Thierry Delcroix (IRD, Noumea) for helpful discussion, and Christophe Menkes (IRD, LODYC) for making ERS + TAO wind stress fields available for this study.

\section{References}

Barnier, B., Siefrift, L., Marchesiello, P., 1995. Thermal forcing for a global ocean circulation model using a three-year climatology of ECMWF analyses. J. Mar. Syst. 6, 363-380.

Barnston, A.G., Glantz, M.H., He, Y., 1999. Predictive skill of statistical and dynamical climate models in SST forecasts during the 1997/98 El Nino episode and the 1998 La Nina onset. Bull. Am. Meteorol. Soc. 80, 217-243.

Bentamy, A., Grima, N., Quilfen, Y., 1996. Validation of the gridded weekly and monthly wind fields calculated from the ERS-1 scatterometer wind observations. Global Atmos. Ocean Syst. 6, 373-396.

Blanke, B., Delecluse, P., 1993. Variability of the Tropical Atlantic Ocean simulated by a general circulation model with two different mixed layer physics. J. Phys. Oceanogr. 23, 1363-1388.

Blayo, E., Verron, J., Molines, J.M., 1994. Assimilation of TOPEX/ POSEIDON altimeter data into a circulation model of the North Atlantic. J. Geophys. Res. 9 (C12), 24691-24705.

Bonekamp, H., van Oldenborgh, G.J., Burgers, G., 2001. Varia- 
tional assimilation of Tropical Atmosphere-Ocean and expendable bathythermograph data in the Hamburg Ocean Primitive Equation ocean general circulation model, adjusting the surface fluxes in the tropical ocean. J. Geophys. Res. 106, $16693-16709$.

Brankart, J.M., Testut, C.E., Brasseur, P., Verron, J., 2003. Multivariate analysis of the 1993-96 satellite observations in the North Atlantic Ocean using an isopycnic coordinate ocean model controlled by a reduced order Kalman filter. J. Geophys. Res. (in press).

Brasseur, P., Ballabrera, J., Verron, J., 1999. Assimilation of altimetric observations in a primitive equation model of the Gulf Stream using a singular evolutive extended Kalman filter. J. Mar. Syst. 22 (4), 269-294.

Cane, M.A., Kaplan, A., Miller, R.N., Tang, B., Hackert, E.C., Busalacchi, A.J., 1996. Mapping tropical Pacific sea level: data assimilation via a reduced state space Kalman filter. J. Geophys. Res. 101 (C10), 22599-22617.

Canizares, R., Kaplan, A., Cane, M.A., Chen, D., Zebiak, S.E., 2001. Use of data assimilation via linear low-order models for the initialization of El Nino-Southern oscillation predictions. J. Geophys. Res. 106, 30947-30959.

Delcroix, T., 1998. Observed surface oceanic and atmospheric variability in the tropical Pacific at seasonal and ENSO timescales: a tentative overview. J. Geophys. Res. 103, 18611-18633.

Delecluse, P., Davey, M.K., Kitamura, Y., Philander, G.H., Suarez, M., Bengtsson, L., 1998. Coupled general circulation of the tropical Pacific. J. Geophys. Res. 103, 14357-14373.

Fu, L.L., Fukumori, I., Miller, R.N., 1993. Fitting dynamic models to Geosat sea-level observations in the tropical Pacific ocean: Part II. A linear, wind-driven model. J. Phys. Oceanogr. 23, 2162-2181.

Fukumori, I., 1995. Assimilation of TOPEX sea level measurements with a reduced-gravity shallow water model of the tropical Pacific Ocean. J. Geophys. Res. 100, 25027-25039.

Gent, P.R., Cane, M.A., 1989. A reduced gravity primitive equation model of the upper equatorial ocean. J. Comput. Phys. 81 (2), $444-480$.

Gourdeau, L., Verron, J., Delcroix, T., Murtuggude, R., Busalacchi, A.J., 2000. Assimilation of Topex/Poseidon altimetric data in a primitive equation model of the tropical Pacific Ocean, during the 1992-1996 El Nino-Southern Oscillation period. J. Geophys. Res. 105 (C4), 8473-8488.

Greiner, E., Arnault, S., 2000. Comparing the results of a 4-D variational assimilation of satellite and in situ data with WOCE CITHER hydrographic measurements in the tropical Atlantic. Prog. Oceanogr. 47, 1-68.

Grima, N., Bentamy, A., Katsaros, K., Quilfen, Y., Delecluse, P., Levy, C., 1999. Sensitivity of an oceanic general circulation model forced by satellite wind fields. J. Geophys. Res. 104, $7967-7989$.
Jackett, D.R., Mc Dougall, T.J., 1995. Minimal adjustment of hydrographic data to achieve static stability. J. Atmos. Oceanic Technol. 12, 381-389.

Kalnay, E.M.K., Kistler, R., Collins, W., Deaven, D., Gandin, L., Iredell, M., Saha, S., White, G., Woolen, J., Zhu, Y., Chelliah, M., Ebisuzaki, W., Higgins, W., Janowiak, J., Mo, K.C., Ropelewski, C., Leetmaa, A., Reynolds, R., Jenne, R., 1996. The NCEP/NCAR reanalysis project. Bull. Am. Metereol. Soc. 77, 437-471.

Latif, M., Sterl, A., Maier-Reimer, E., Junge, M.M., 1993. Structure and predictability of the El Niño/Southern Oscillation phenomenon in a coupled ocean-atmosphere general circulation model. J. Clim. 6, 700-708.

Madec, G., Delecluse, P., Imbard, M., Levy, C., 1998. OPA 8.1 general circulation model reference manual. Notes de l'IPSL no. 11, 91 pp. Université P. et M. Curie, Paris, 1998.

Menkes, C., Boulanger, J.P., Busalachi, A.J., Vialard, J., Delecluse, P., McPhaden, M.J., Hackert, E., Grima, N., 1998. Impact of TAO vs. ERS wind stresses onto simulations of the tropical Pacific Ocean during the 1993-1998 period by the OPA OGCM. Climate Impact of Scale Interactions for the Tropical Ocean-Atmosphere System. Euroclivar Workshop Report, vol. 13, pp. 46-48.

Pham, D.T., Verron, J., Roubaud, M.C., 1998. Singular evolutive extended Kalman Filter with EOF initialization for data assimilation in oceanography. J. Mar. Syst. 16 (3-4), 323-340.

Picaut, J., Busalacchi, A.J., McPhaden, M.J., Gourdeau, L., Gonzalez, F.I., Hackert, E.C., 1995. Open-ocean validation of Topex/Poseidon sea level in the western equatorial Pacific. J. Geophys. Res. 100, 25109-25127.

Testut, C.E., Brasseur, P., Brankart, J.M., Verron, J., 2003. Assimilation of sea-surface temperature and altimetric observations during 1992-1993 into an eddy permitting primitive equation model of the North Atlantic Ocean. J. Mar. Syst., this issue.

Verron, J., Gourdeau, L., Pham, D.T., Murtugudde, R., Busalacchi, A.J., 1999. An extended Kalman filter to assimilate satellite altimeter data into a non-linear numerical model of the tropical Pacific: method and validation. J. Geophys. Res. 104, $5441-5458$.

Vialard, J., Menkes, C., Boulanger, J.P., Delecluse, P., Guilyardi, E., Mc Phaden, M., Madec, G., 2001. A model study of oceanic mechanisms affecting equatorial Pacific sea surface temperature during 1997-98 the El Niño. J. Phys. Oceanogr. 31 (7), 1649-1675.

Vossepoel, F.C., Behringer, D.W., 2000. Impact of sea level assimilation on salinity variability in the western equatorial Pacific. J. Phys. Oceanogr. 30, 1706-1721.

Wyrtki, K., 1985. Water displacements in the Pacific and the genesis of El Nino cycles. J. Geophys. Res. 90 (C4), 7129-7132. 